\title{
LA CRISIS DEL TRANSPORTE FERROVIARIO DE MERCANCÍAS EN GALICIA: UNA POTENCIALIDAD NO APROVECHADA EN LA CADENA INTERMODAL DEL TRANSPORTE. 1970-2010
}

\section{The crisis of railway transportation of goods in Galicia: a potentiality not used in the intermodal transport chain. 1970-2010}

\author{
José Antonio Díaz Fernández \\ UVIGO. IGETI
}

Recibido: $13 / 03 / 20$

Aceptado: 20/06/20

\begin{abstract}
Resumen
El sistema de transportes y comunicaciones en Galicia presenta unos marcados síntomas de bajo nivel de integración de la cadena multimodal del transporte. La articulación del sistema de transportes está funcionando en unos estándares de participación muy lateralizados a favor de la carretera. Por su parte, la concurrencia en el mercado del transporte por ferrocarril arroja unos valores de acentuada marginalidad en su cuota de mercado. La evolución del transporte de mercancías por ferrocarril en Galicia nos aclara dos factores. Por un lado, la demanda de desplazamiento de mercancías por el tren ha sido siempre regresiva en sus principales segmentos del mercado. Por su parte, los valores de la carretera han sido siempre expansivos. En segundo lugar, las elevadas potencialidades que presenta el ferrocarril se encuentran muy sub-explotadas. La dotación de infraestructuras del transporte no ofrece una óptima conexión puerto-ferrocarril para impulsar el flujo de mercancías con matriz de viaje O-D en Galicia.
\end{abstract}

\section{Abstract}

The transport and communications system in Galic ia presents marked symptoms of a low level of integration of the multimodal transport chain. The articulation of the transport system is operating in very lateralized participation standards in favor of the road. For its part, competition in the rail transport market shows values of marked marginality in its market share. The evolution of rail freight transport in Galicia clarifies two factors. On the one hand, the demand for the movement of goods by train has always been regressive in its main market segments. On the other hand, the values of the highway have always been expansive. Secondly, the high potential of the railway is highly under-exploited. The provision of transport infrastructure does not offer an optimal port-rail connection to promote the flow of goods with an O-D travel matrix in Galicia. The poor modal articulation of the two transport systems translates into:

a) A drop in the records of the volume of the tonnage moved by the train. 
La mala articulación modal de los dos sistemas de transporte se traduce en:

a) Una caída en los registros del volumen del tonelaje movilizado por el tren.

b) La pérdida de nichos de mercado a favor de la carretera.

c) La pérdida de relaciones territoriales en la matriz de viaje $\mathrm{O}-\mathrm{D}$.

d) La baja especialización operativa del tren gallego al concurrir en el mercado del transporte.

\section{Palabras clave}

Conectividad, accesibilidad, intermodalidad, operatividad, cadena intermodal del transporte, Redes Transeuropeas del Transporte (R.T.E.-T), stock de capital público. b) The loss of market niches in favor of the road.

c) The loss of territorial relations in the 0-D travel matrix.

d) The low operational specialization of the Galician train when competing in the transport market.

\section{Keywards}

Connectivity, accessibility, intermodality, operability, intermodal transport chain, TransEuropean Transport Networks (R.T.E.-T), public capital stock. 


\section{Introducción}

Los transportes de mercancías en Galicia por ferrocarril están experimentando una notable pérdida de cota de mercado. Este factor explica que la demanda potencial de transporte se está desplazando del ferrocarril al transporte por carretera. Así, los registros de la demanda aún son más elevados que los que ya tenía. Este proceso genera importantes problemas a la operatividad de la malla viaria. Por un lado, se están incrementando notablemente los niveles de congestión vial. Por otra parte, se están generando intensos procesos de colisión de tráficos que operan con diferentes matrices de viaje O-D. Por todo ello, es menester que se realice una política del transporte destinada a impulsar y vitalizar la participación del ferrocarril en el mercado regional y nacional del transporte. Las líneas a desarrollar son básicamente tres. En primer lugar, la ganancia en estándares de calidad de servicio para concurrir en el mercado con plenas garantías de éxito y eficacia. En segundo lugar, se deberá impulsar la consecución de una integración modal donde el ferrocarril comercialice una oferta de transporte idónea a cada segmento del mercado. Para ello, será preciso que se ponga paralelamente en marcha un Plan Empresarial en el cual se trata de fidelizar a la demanda con una política tarifaria y de calidad de la oferta ajustada a las necesidades del mercado del transporte. En tercer y último lugar, será una actuación clave la propuesta de articular modalmente las terminales portuarias gallegas, los centros industriales y los puntos de almacenamiento y logística. El objetivo aquí es que el ferrocarril ocupe una posición geoestratégica dentro del mercado gallego del transporte que en el presente está atendida por la carretera.

\section{La naturaleza de las mercancías movilizadas por ferrocarril con matriz de viaje $\mathrm{O}-\mathrm{D}$ en las provincias de Galicia}

Al centrarnos en el estudio del transporte ferroviario de mercancías por ferrocarril para Galicia trataremos de analizar los caracteres que refleja el conjunto español. ${ }^{1}$ En la tabla $n^{\circ} 2.1$ se han consignado los principales productos movilizados en la serie temporal 1975-2000. Las cifras reflejadas en la tabla nos proporcionan una detallada información a propósito de la naturaleza de los principales tráficos movilizados por tren en España. Si nos centramos en la naturaleza de las mercancías,

1 RENFE. 100 Datos Estadísticos (Varios años). Edit. RENFE. Madrid. Cabe apuntar, como se explicita en el pie de las notas de la tabla, que la elaboración de los registros estadísticos en el 2000 no está a cargo del Departamento de Informática de la compañía RENFE. En esta ocasión el origen de los registros corre a cargo del Departamento de Comunicación Corporativa y Relaciones Externas. 
descubrimos lo apuntado más arriba al definir los trazos del transporte ferroviario español y gallego: mercancías muy voluminosas, materias primas en bruto, mercancías de elevado tonelaje, materia prima dotada de un escaso valor añadido. Se trata de un tipo de productos poco exigentes en estándares de accesibilidad territorial, etc. El único segmento que rompe con la tendencia descrita es el referido al tráfico de automóviles. Este patrón de transporte se repite para todos los registros ferroviarios en Galicia y España.

Entre los campos referidos a las mercancías movilizadas por el ferrocarril español apreciamos como en la tabulación de los registros por parte del Departamento de Informática de RENFE se han producido varios cambios en la metodología. Así, apreciamos que existen tráficos de mercancías que se mantienen durante un reducido número de ejercicios. Por su parte, se aprecia cómo han aparecido otros nuevos. No se trata tanto de un producto de nueva movilización como de uno que anteriormente estaba cuantificado en términos agregados: es el caso de los cementos y las calizas. Por otro lado, se aprecia como en la serie estadística confeccionada aparecen las maderas en un momento concreto y se consolidan para la mayor parte de la serie. Por último, al ir perfeccionándose el tratamiento estadístico descubrimos como el Departamento de Informática de RENFE opta por desagregar los tráficos de vehículos militares de los de automóviles. Asimismo, en el último de los registros consignados en la serie, ejercicio de 2000, aparecen dos novedades al tabular los valores. En primer lugar, se consignan tráficos internacionales y otros. En segundo lugar, la cuantificación de los registros ya no está a cargo del Departamento de Informática, si no de la Dirección de Comunicación Corporativa y Relaciones Externas.

La tendencia seguida por el tráfico ferroviario español de mercancías nos permitirá establecer comparaciones con el de las provincias gallegas y el conjunto español. Para empezar, podremos analizar si en Galicia y España el ferrocarril ha experimentado una tendencia expansiva en captación de cuota de mercado o, por el contrario, si conoce una pérdida de vitalidad en el valor de los tráficos de mercancías. La serie española nos aclara esto último: claro retroceso de tráfico de mercancías movilizado por el tren. Por otro lado, podemos conocer con precisión cuáles son los segmentos que totalizan los más elevados valores en el ranking y su tendencia en el conjunto de la serie.

Las principales mercancías que recurren al ferrocarril para cubrir sus desplazamientos son, por este orden, los minerales, los carbones minerales, los combustibles líquidos, los productos siderúrgicos, los productos agrarios (cereal), e iberiatarifa, los abonos y los automóviles. Ahora bien, si se examina con detalle la evolución de estos productos se advierten tres tendencias claras. En primer lugar, existe un grupo de ellos que ha experimentado una pérdida clara de volumen de las mercancías movilizadas: los minerales, el combustible líquido, los productos agrarios y los cemen- 
tos. En segundo lugar, detectamos otro grupo de productos que se ha mantenido relativamente estable con débiles oscilaciones a la baja y de subida en el conjunto del período: carbón mineral, maderas, butanos y propanos, y los productos siderúrgicos. En tercer lugar, existe un conjunto de bienes que han ido incrementando el valor del tonelaje movilizado para toda la serie temporal: iberiatarifa, automóviles.

\begin{tabular}{|c|c|c|c|c|c|c|c|}
\hline \multicolumn{7}{|c|}{$\begin{array}{l}\text { Tabla n' 2.1. Evolución de los principales tráficos ferroviarios nacionales de mercancías } \\
\text { efectuados en vagón completo según la composición de las cargas correspondientes al } \\
\text { período } 1975-1998 \text {. Valores en miles de Tn). }\end{array}$} \\
\hline Mercancías. & 1975 & 1980 & 1985 & 1990 & 1995 & 1998 & 2000 \\
\hline Cereal & 1.374 & 1.419 & 2.024 & 1.201 & 1.178 & 1.146 & 1.176 \\
\hline Remolacha & 503 & $1.911^{1}$ & -- & -- & -- & -- & -- \\
\hline Maderas & -- & -- & 690 & 623 & 594 & 580 & 678 \\
\hline Carb.miner. & 2.944 & 2.984 & 2.597 & 2.190 & 2.295 & 1.978 & 2.015 \\
\hline Cementos & 4.357 & 4.065 & 2.8673 & $2.62^{3}$ & 1.828 & 1.953 & 1.792 \\
\hline Minerales & 7.411 & 7.229 & 5.270 & 2.495 & 1.976 & 135 & 137 \\
\hline Prod.sider. & 3.010 & 2.254 & 2.846 & 3.008 & 3.103 & 3.361 & 3.397 \\
\hline Com.líquid. & 7.365 & 5.975 & 1.739 & 1.650 & 537 & 697 & 801 \\
\hline Prod.quími. & 355 & 624 & 971 & 1.012 & 640 & 691 & 623 \\
\hline Buta.yprop. & 524 & 609 & 506 & 723 & 543 & 699 & 674 \\
\hline Abonos & 1.330 & 1.286 & 1.248 & 717 & 417 & 500 & 427 \\
\hline Automóvil & 385 & 425 & 494 & 501 & 460 & 776 & 700 \\
\hline Automóvil militar & -- & 1592 & 157 & 135 & 24 & 38 & 39 \\
\hline Iberiatarifa & 1.091 & 1.013 & 671 & 202 & 75 & 738 & 2.102 \\
\hline Total & 30.649 & 29.953 & 21.923 & 16.943 & 13.646 & 13.254 & $14.561^{4}$ \\
\hline
\end{tabular}

Fuente: Departamento de Informática. RENFE. 100 datos estadísticos. Elaboración propia.

(1) A partir de 1979-1980 no se consigna en la fuente 100 datos estadísticos 1979-80-81 las mercancías correspondientes a remolacha. Para no romper la serie hemos tenido que buscar el registro interno de este valor que ostentaba el Departamento de Informática. En el lugar de remolacha se pasa a cuantificar las maderas. Este registro no existía en la publicación de 100 datos estadísticos 1975-76-77.

(2) Aparecen desagregados los transportes militares desde 1985. En 1979 en el apartado automóviles aparecen consignados los valores correspondientes a vehículos militares y automóviles. No se especificaba cada partida por separado.

(3) A partir de 1982 se consigna en la misma fila el transporte de cemento y calizas. En el ejercicio de 1987 el Departamento de Informática desagrega en dos filas diferentes estos productos.

(4) En el registro de 2000 aparecen consignados los tráficos internacionales y otros. Estos últimos son un registro nuevo. Por otro lado, la publicación de las estadísticas de transporte ferroviario no lo efectúa el anterior Departamento de Informática. A partir de este período esta actividad corre a cargo de la Dirección de Comunicación Corporativa y Relaciones Externas. 
Por lo que confiere al perfil que evidencia la matriz de viaje O-D de los tipos de productos llegados o salidos de cada una de las provincias de Galicia, cabe empezar el comentario con dos notas. La primera nos recuerda lo anotado a los pies de página de las tablas. En efecto, la Dirección de informática RENFE no había realizado la computación de los principales productos movilizados por provincia hasta el año 1996. La segunda nos aclara que los registros internos de la UNE Regionales RENFE no se hacían públicos los valores. Los mismos fueron construidos en términos agregados y se consignaba la cifra de totales de Galicia. Por otro lado, a partir de 1991 disponemos de registros para los flujos ferroviarios de Galicia. Estos valores, como hemos indicado, se efectuaban para las principales estaciones y se publicaban en totales. En las tablas n ${ }^{\circ} 10.4 .2$ y 10.4.3 tenemos la oportunidad de conocer con detalle cuáles eran las principales mercancías que salían o entraban en Galicia. El estudio del tipo de mercancías movilizadas por tren con matriz de viaje O-D fijado en las provincias gallegas revela cuatro cuestiones de interés:

a) Los tráficos ferroviarios de mercancías con extremo de viaje en Galicia presentan un claro paralelismo con el transporte español de mercancías.

b) Los principales tráficos movilizados pertenecen a un segmento que tiene por características principales, salvo el de automóviles, a los siguientes trazos. Se trata de mercancías muy voluminosas, muy pesadas, preferencialmente materia prima en bruto o con un escaso nivel de transformación final. Se trata de mercancías de poco valor añadido al comercializarse en los mercados salvo los tráficos de automóviles.

c) Los tráficos movilizados hacia o desde las terminales gallegas presentan como perfil tipo más significativo el ser unos productos poco exigentes en niveles de accesibilidad territorial.

d) El volumen de las mercancías llegadas o salidas de Galicia responden a dos trazos fundamentales. En primer lugar, se trata de una parte de la producción final gallega que se destina bien hacia el mercado interior español, hacia los mercados internacionales o hacia el mercado intrarregional (madera, piedra, cementos, arenas, gravas, automóviles, etc.). El segundo de los rasgos nos explica que Galicia es una puerta de entrada o salida de las mercancías producidas en las CC.AA. que ostentan una dotación de conectividad adecuada. Se trata de tráficos de tránsito que se destinan hacia las principales terminales portuarias como paso previo a su canalización hacia el mercado exterior. En paralelo, existe un porcentaje de mercancías que tienen como destino a Galicia que se orientan a nutrir el sistema productivo gallego.

Por otra parte, las cifras glosadas en la tabla $n^{\circ} 2.2$ nos muestran con total detalle cuál es la intensidad de los tráficos ferroviarios registrados en el conjunto de los tramos de la Gerencia del Eje del Noroeste. Se ha realizado un esfuerzo por 
desagregar el valor de los tráficos ferroviarios en cada uno de los tramos. Los valores alcanzados nos explican el comportamiento de siete magnitudes:

a) La longitud de viaje O-D de las relaciones gestionadas por la Gerencia del Eje del Noroeste.

b) El valor del número de trenes-km efectuados en los tramos para el segmento de viajeros y mercancías.

c) La densidad media de circulación por kilómetro y día correspondiente a los tráficos de viajeros y mercancías.

d) El valor de las Toneladas Brutas Kilómetro Remolcadas (T.B.K.R.), correspondientes a cada tramo del Eje del Noroeste.

e) El total de las Toneladas-kilómetro netas (Tn-km netas.) movilizadas en cada itinerario del Eje del Noroeste.

f) El nivel de la densidad de carga transportada por kilómetro y día.

g) La densidad de remolque por kilómetro y día.

\begin{tabular}{|c|c|c|c|c|c|c|}
\hline \multicolumn{3}{|c|}{ Trayectos gerencia NW. } & \multicolumn{2}{|c|}{ Trenes-Km. (miles) } & \multicolumn{2}{|c|}{$\begin{array}{l}\text { Densidad media de } \\
\text { circulación (por km y día) }\end{array}$} \\
\hline Denominación & Número & Kilómetros & Viajeros & Mercancías & Viajeros & Mercancías \\
\hline Palencia-León & 150 & 122 & $1.670,9$ & $1.322,5$ & 37,5 & 29,7 \\
\hline León-Ujo. & 151 & 115 & 932,1 & 729,7 & 22,2 & 17,4 \\
\hline $\begin{array}{l}\text { Ujo-Lugo de } \\
\text { Ilanera. }\end{array}$ & 152 & 34 & $1.061,2$ & 179,6 & 85,5 & 14,5 \\
\hline $\begin{array}{l}\text { Lugo de Llanera- } \\
\text { Gijón. }\end{array}$ & 153 & 22 & 574,5 & 63,6 & 71,5 & 7,9 \\
\hline $\begin{array}{l}\text { Soto de Rey-El } \\
\text { Entrego. }\end{array}$ & 160 & 22 & 183,0 & 26,6 & 22,8 & 3,3 \\
\hline $\begin{array}{l}\text { Tudela Veguín- } \\
\text { Lugo de Llanera. }\end{array}$ & 161 & 14 & , 8* & 48,3 &, $2^{*}$ & 9,5 \\
\hline Oviedo-Trubia. & 162 & 13 & 109,8 &, $4^{*}$ & 23,1 &, $1^{*}$ \\
\hline $\begin{array}{l}\text { Lugo Llanera- } \\
\text { Nubledo. }\end{array}$ & 163 & 11 & 10,1 & 63,6 & 2,5 & 15,8 \\
\hline $\begin{array}{l}\text { Nubledo-San } \\
\text { Juan de Nieva }\end{array}$ & 164 & 10 & 333,7 & 9,7 & 91,4 & 2,7 \\
\hline Nubledo-Trasona. & 165 & 6 &, $0 *$ & 20,7 &, $0 *$ & 9,5 \\
\hline Veriña-Aboño. & 166 & 2 &, $1^{*}$ & 5,2 &, $1^{*}$ & 7,1 \\
\hline León-Astorga. & 200 & 52 & 415,0 & 383,1 & 21,9 & 20,2 \\
\hline
\end{tabular}




\begin{tabular}{|c|c|c|c|c|c|c|}
\hline \multicolumn{3}{|c|}{ Trayectos gerencia NW. } & \multicolumn{2}{|c|}{ Trenes-Km. (miles) } & \multicolumn{2}{|c|}{$\begin{array}{l}\text { Densidad media de } \\
\text { circulación (por km y día) }\end{array}$} \\
\hline Denominación & Número & Kilómetros & Viajeros & Mercancías & Viajeros & Mercancías \\
\hline $\begin{array}{l}\text { Astorga- } \\
\text { Ponferrada }\end{array}$ & 201 & 77 & 580,7 & 557,9 & 20,7 & 19,9 \\
\hline $\begin{array}{l}\text { Ponferrada- } \\
\text { Monforte de } \\
\text { Lemos }\end{array}$ & 202 & 110 & 776,5 & 854,1 & 19,3 & 21,3 \\
\hline $\begin{array}{c}\text { Monforte- } \\
\text { Betanzos Infesta }\end{array}$ & 203 & 163 & 883,9 & 503,2 & 14,9 & 8,5 \\
\hline $\begin{array}{c}\text { Betanzos } \\
\text { Infesta-A Coruña } \\
\text { San Diego }\end{array}$ & 204 & 23 & 163,7 & 53,5 & 19,5 & 6,4 \\
\hline $\begin{array}{l}\text { Bifurc. El Burgo } \\
\text { A Coruña-San } \\
\text { Critóbal }\end{array}$ & 205 & 5 & 38,7 & 6,7 & 21,2 & 3,7 \\
\hline $\begin{array}{c}\text { Toral de Vados- } \\
\text { Villafranca del } \\
\text { Bierzo }\end{array}$ & 206 & 9 &, $3^{*}$ & 4,8 &, $1^{*}$ & 1,5 \\
\hline $\begin{array}{c}\text { Betanzos Infesta- } \\
\text { Ferrol }\end{array}$ & 210 & 43 & 254,7 & 28,0 & 16,2 & 1,8 \\
\hline $\begin{array}{c}\text { Monforte de } \\
\text { Lemos-Ourense } \\
\text { Empalme }\end{array}$ & 220 & 45 & 346,6 & 280,4 & 21,1 & 17,7 \\
\hline $\begin{array}{l}\text { Ourense } \\
\text { Empalme- } \\
\text { Guillarei }\end{array}$ & 221 & 95 & 639,3 & 517,7 & 18,4 & 14,9 \\
\hline $\begin{array}{l}\text { Guillarei- } \\
\text { Redondela } \\
\end{array}$ & 222 & 25 & 170,8 & 126,7 & 18,7 & 13,9 \\
\hline Redondela-Vigo & 223 & 12 & 231,0 & 53,3 & 52,7 & 12,2 \\
\hline $\begin{array}{c}\text { Guillarei-Valença } \\
\text { do Minho }\end{array}$ & 224 & 6 &, $6^{*}$ & 3,5 &, $3^{*}$ & 1,6 \\
\hline $\begin{array}{l}\text { Redondela- } \\
\text { Santiago }\end{array}$ & 230 & 91 & 789,3 & 77,7 & 23,8 & 2,3 \\
\hline $\begin{array}{l}\text { Ourense } \\
\text { Empalme- } \\
\text { Santiago }\end{array}$ & 313 & 130 & 657,5 & 298,7 & 13,9 & 6,3 \\
\hline $\begin{array}{c}\text { Santiago-A } \\
\text { Coruña San } \\
\text { Cristóbal }\end{array}$ & 314 & 75 & 619,1 & 75,1 & 22,6 & 2,7 \\
\hline Total & & & $11.443,9$ & $6.304,3$ & 23,5 & 13,0 \\
\hline
\end{tabular}

Fuente: RENFE. Dirección de Informática. Elaboración Propia.

(*) La fuente estadística manejada por la Dirección de Informática de RENFE ha computado en el registro la parte decimal y no la parte entera. Por ello, debemos pensar que la parte entera es cero (0). 


\begin{tabular}{|c|c|c|c|c|c|c|}
\hline \multicolumn{7}{|c|}{$\begin{array}{l}\text { Tabla } n^{\circ} 2.2 \text {. (Continuación). Cuadro de resultados de la operatividad del transporte ferroviario } \\
\text { correspondiente a los trayectos desarrollados por RENFE en la Gerencia del Eje Noroeste. } \\
2004 \text {. }\end{array}$} \\
\hline \multirow{2}{*}{$\begin{array}{l}\text { Trayectos Gerencia } \\
\text { NW. } \\
\text { Denominación }\end{array}$} & \multirow{2}{*}{$\begin{array}{l}\text { Tn-km Netas } \\
\qquad\left(10^{6}\right) \\
\text { Mercancías }\end{array}$} & \multirow{2}{*}{$\begin{array}{c}\text { Densidad de } \\
\text { carga (por } \\
\text { km/día) }\end{array}$} & \multicolumn{2}{|c|}{ T.K.B.R. (Millones) } & \multicolumn{2}{|c|}{$\begin{array}{l}\text { Densidad de remolque } \\
\text { (por km y día) }\end{array}$} \\
\hline & & & Viajeros & Mercancías & Viajeros & Mercancías \\
\hline Palencia-León & 402,0 & $9.027,6$ & 442,2 & 875,2 & $9.930,4$ & $19.654,2$ \\
\hline León-Ujo & 223,0 & $5.312,7$ & 191,4 & 473,0 & $4.559,9$ & $11.268,6$ \\
\hline Ujo-Lugo de llanera & 58,5 & $4.713,9$ & 153,6 & 117,8 & $12.377,1$ & $9.492,3$ \\
\hline Lugo de Llanera-Gijón & 17,7 & $2.204,2$ & 83,6 & 38,5 & $10.411,0$ & $4.794,5$ \\
\hline Soto de Rey-El Entrego & 5,5 & 684,9 & 21,8 & 14,3 & $2.714,8$ & $1.780,8$ \\
\hline $\begin{array}{c}\text { Tudela Veguín-Lugo de } \\
\text { Llanera }\end{array}$ & 10,9 & $2.133,1$ &, $1^{*}$ & 27,3 & 19,6 & $5.342,5$ \\
\hline Oviedo-Trubia &, $0 *$ & 0 & 14,2 &, $1^{*}$ & $2.992,6$ & 21,1 \\
\hline Lugo Llanera-Nubledo & 20,7 & $5.155,7$ & 1,8 & 43,0 & 448,3 & $10.709,8$ \\
\hline $\begin{array}{c}\text { Nubledo-San Juan de } \\
\text { Nieva } \\
\end{array}$ & 2,2 & 602,7 & 44,1 & 5,0 & $12.082,2$ & $1.369,9$ \\
\hline Nubledo-Trasona & 7,3 & $3.333,3$ &, $0^{*}$ & 15,0 &, $0 *$ & $6.849,3$ \\
\hline Veriña-Abońo & 1,5 & $2.054,8$ &, $0 *$ & 3,3 &, $0 *$ & $4.520,5$ \\
\hline León-Astorga & 73,2 & $3.856,7$ & 119,5 & 180,4 & $6.296,1$ & $9.504,7$ \\
\hline Astorga-Ponferrada & 106,6 & $3.792,9$ & 168,5 & 261,2 & $5.995,4$ & $9.293,7$ \\
\hline $\begin{array}{c}\text { Ponferrada-Monforte } \\
\text { de Lemos }\end{array}$ & 179,5 & $4.470,7$ & 233,8 & 428,7 & $5.823,2$ & $10.677,5$ \\
\hline $\begin{array}{c}\text { Monforte-Betanzos } \\
\text { Infesta }\end{array}$ & 87,6 & $1.472,4$ & 210,1 & 210,2 & $3.531,4$ & $3.533,1$ \\
\hline $\begin{array}{c}\text { Betanzos Infesta-A } \\
\text { Coruña San Diego }\end{array}$ & 9,3 & $1.07,8$ & 31,3 & 23,0 & $3.728,4$ & $2.739,7$ \\
\hline $\begin{array}{c}\text { Bifurc. El Burgo A } \\
\text { Coruña-San Critóbal }\end{array}$ & ,9* & 493,2 & 7,4 & 2,2 & $4.054,8$ & $1.205,5$ \\
\hline $\begin{array}{c}\text { Toral de Vados- } \\
\text { Villafranca del Bierzo }\end{array}$ & 1,5 & 456,6 &, $0^{*}$ & 2,8 &, $0^{*}$ & 852,4 \\
\hline $\begin{array}{c}\text { Betanzos Infesta- } \\
\text { Ferrol }\end{array}$ & 3,6 & 229,4 & 47,2 & 8,8 & $3.007,3$ & 560,7 \\
\hline $\begin{array}{l}\text { Monforte de Lemos- } \\
\text { Ourense Empalme }\end{array}$ & 58,7 & $3.573,8$ & 74,8 & 135,6 & $4.554,0$ & $8.255,7$ \\
\hline $\begin{array}{c}\text { Ourense Empalme- } \\
\text { Guillarei }\end{array}$ & 84,5 & $2.436,9$ & 170,2 & 211,7 & $4.908,4$ & $6.105,3$ \\
\hline Guillarei-Redondela & 19,9 & $2.180,8$ & 45,2 & 50,3 & $4.953,4$ & $5.512,3$ \\
\hline Redondela-Vigo & 6,8 & $1.552,5$ & 46,6 & 18,5 & $10.639,3$ & $4.223,7$ \\
\hline $\begin{array}{c}\text { Guillarei-Valença do } \\
\text { Minho }\end{array}$ &, $3 *$ & 137,0 &, $1^{*}$ &, $9 *$ & 45,7 & 411,0 \\
\hline
\end{tabular}




\begin{tabular}{|c|c|c|c|c|c|c|}
\hline $\begin{array}{c}\text { Trayectos Gerencia } \\
\text { NW. }\end{array}$ & $\begin{array}{c}\text { Tn-km Netas } \\
\left(10^{6}\right)\end{array}$ & $\begin{array}{c}\text { Densidad de } \\
\text { carga (por } \\
\text { km/día) }\end{array}$ & \multicolumn{2}{|c|}{ T.K.B.R. (Millones) } & \multicolumn{2}{c|}{$\begin{array}{c}\text { Densidad de remolque } \\
\text { (por km y día) }\end{array}$} \\
\hline Denominación & Mercancías & Kilómetros & Viajeros & Mercancías & Viajeros & Mercancías \\
\hline Redondela-Santiago & 10,7 & 322,1 & 145,6 & 26,1 & $4.383,6$ & 785,8 \\
\hline $\begin{array}{c}\text { Ourense Empalme- } \\
\text { Santiago }\end{array}$ & 58,1 & $1.224,4$ & 154,2 & 122,4 & $3.249,7$ & $2.579,6$ \\
\hline $\begin{array}{c}\text { Santiago-A Coruńa San } \\
\text { Cristóbal }\end{array}$ & 12,4 & 453,0 & 138,2 & 27,5 & $5.048,4$ & $1.004,6$ \\
\hline Total & $1.462,9$ & $3.009,0$ & $2.545,5$ & $3.322,8$ & $5.235,7$ & $6.834,5$ \\
\hline
\end{tabular}

Fuente: RENFE. Dirección de Informática. Elaboración propia.

(*) La fuente estadística manejada por la Dirección de Informática de RENFE ha computado en el registro la parte decimal y no la parte entera. Por ello, debemos pensar que la parte entera es cero (0).

La tabla $n^{\circ} 2.2$ se complementa con la construcción de los valores de la n ${ }^{\circ} 2.3$. En esta ocasión hemos practicado un filtrado a las magnitudes computadas y a los tramos de la Gerencia del Eje del Noroeste. Nótese como en la elaboración de la tabla únicamente se han consignado los registros correspondientes a los tramos ferroviarios de Galicia. En paralelo, y como en esta sección nos estamos ocupando del comentario de los tráficos de mercancías, se han tabulado únicamente los flujos de mercancías generados o atraídos en cada tramo. El resultado de la modificación de la $n^{\circ} 2.2$ es la ganancia en nivel de sencillez y concreción en el contenido de la información. Si nos centramos en los valores del tráfico de mercancías movilizado por tren destacaremos la importancia de los tramos: Ponferrada-Monforte de Lemos, Monforte de Lemos-Empalme Ourense, Ourense Empalme-Guillarei, Guillarei-Redondela y Ourense Empalme-Santiago.

\begin{tabular}{|c|c|c|c|c|}
\hline \multicolumn{6}{|c|}{ Tabla $n^{\circ}$ 2.3. Cuadro de resultados de la operatividad del transporte ferroviario } \\
correspondiente a los trayectos desarrollados por RENFE en la Gerencia del Eje Noroeste. \\
Tramos gallegos. 2004.
\end{tabular}




\begin{tabular}{|c|c|c|c|c|}
\hline Denominación & Número & Kilómetros & Mercancías & Mercancías \\
\hline Guillarei-Redondela. & 222 & 25 & 126,7 & 13,9 \\
\hline Redondela-Vigo. & 223 & 12 & 53,3 & 12,2 \\
\hline Guillarei-Valença do Minho. & 224 & 6 & 3,5 & 1,6 \\
\hline Redondela-Santiago. & 230 & 91 & 77,7 & 2,3 \\
\hline Ourense Empalme-Santiago & 313 & 130 & 298,7 & 6,3 \\
\hline Santiago-A Coruńa San Cristóbal. & 314 & 75 & 75,1 & 2,7 \\
\hline Total. & & & $6.304,3$ & 13,0 \\
\hline
\end{tabular}

Fuente: RENFE. Dirección de Informática. Elaboración Propia.

(*) La fuente estadística manejada por la Dirección de Informática de RENFE ha computado en el registro la parte decimal y no la parte entera. Por ello, debemos pensar que la parte entera es cero (0).

Tabla $n^{\circ}$ 2.3. (Continuación). Cuadro de resultados de la operatividad del transporte ferroviario correspondiente a los trayectos desarrollados por RENFE en la Gerencia del Eje Noroeste. Tramos gallegos. 2004.

\begin{tabular}{|c|c|c|c|c|}
\hline Trayectos Gerencia NW. & $\begin{array}{c}\text { Tn-km Netas } \\
\left(10^{6}\right)\end{array}$ & $\begin{array}{l}\text { Densidad de carga } \\
\text { (por km/día) }\end{array}$ & T.K.B.R. & $\begin{array}{c}\text { Densidad de remolque } \\
\text { (por km y día) }\end{array}$ \\
\hline Denominación & Mercancías & Kilómetros & Mercancías & Mercancías \\
\hline $\begin{array}{c}\text { Ponferrada-Monforte de } \\
\text { Lemos }\end{array}$ & 179,5 & $4.470,7$ & 428,7 & $10.677,5$ \\
\hline Monforte-Betanzos Infesta & 87,6 & $1.472,4$ & 210,2 & $3.533,1$ \\
\hline $\begin{array}{c}\text { Betanzos Infesta-A Coruña } \\
\text { San Diego }\end{array}$ & 9,3 & $1.07,8$ & 23,0 & $2.739,7$ \\
\hline $\begin{array}{c}\text { Bifurc. El Burgo A Coruña- } \\
\text { San Cristóbal }\end{array}$ & $9 *$ & 493,2 & 2,2 & $1.205,5$ \\
\hline $\begin{array}{c}\text { Toral de Vados-Villafranca } \\
\text { del Bierzo }\end{array}$ & 1,5 & 456,6 & 2,8 & 852,4 \\
\hline Betanzos Infesta-Ferrol & 3,6 & 229,4 & 8,8 & 560,7 \\
\hline $\begin{array}{c}\text { Monforte de Lemos- } \\
\text { Ourense Empalme }\end{array}$ & 58,7 & $3.573,8$ & 135,6 & $8.255,7$ \\
\hline Ourense Empalme-Guillarei & 84,5 & $2.436,9$ & 211,7 & $6.105,3$ \\
\hline Guillarei-Redondela & 19,9 & $2.180,8$ & 50,3 & $5.512,3$ \\
\hline Redondela-Vigo & 6,8 & $1.552,5$ & 18,5 & $4.223,7$ \\
\hline Guillarei-Valença do Minho &, $3^{*}$ & 137,0 &, $9 *$ & 411,0 \\
\hline Redondela-Santiago & 10,7 & 322,1 & 26,1 & 785,8 \\
\hline Ourense Empalme-Santiago & 58,1 & $1.224,4$ & 122,4 & $2.579,6$ \\
\hline $\begin{array}{l}\text { Santiago-A Coruña San } \\
\text { Cristóbal } \\
\end{array}$ & 12,4 & 453,0 & 27,5 & $1.004,6$ \\
\hline Total & $1.462,9$ & $3.009,0$ & $3.322,8$ & $6.834,5$ \\
\hline
\end{tabular}

Fuente: RENFE. Dirección de Informática. Elaboración propia.

(*) La fuente estadística manejada por la Dirección de Informática de RENFE ha computado en el registro la parte decimal y no la parte entera. Por ello, debemos pensar que la parte entera es cero (0). 
No obstante, los valores totalizados por los tramos gallegos no resultan equiparables a los alcanzados por otras relaciones en la Gerencia del Eje del Noroeste en: Palencia-León, León-Ujo, Ujo-Lugo de Llanera. La desigual movilización de mercancías en el conjunto de los tramos del Eje del Noroeste explica como las mayores densidades se localizan entre León-Palencia y Asturias.

\subsection{La naturaleza de las mercancías movilizadas por ferrocarril con matriz de viaje O-D en las provincias de Galicia.}

Al centrarnos en el estudio del transporte ferroviario de mercancías por ferrocarril para Galicia trataremos de analizar, inicialmente, los caracteres que refleja el conjunto español. ${ }^{2}$ En la tabla n ${ }^{\circ} 2.4$ se han consignado los principales productos movilizados en la serie temporal 1975-2000. Las cifras reflejadas en la tabla nos proporcionan una detallada información a propósito de la naturaleza de los principales tráficos movilizados por tren en España. Si nos centramos en la naturaleza de las mercancías, descubrimos lo apuntado más arriba al definir los trazos del transporte ferroviario español y gallego: mercancías muy voluminosas, materias primas en bruto, mercancías de elevado tonelaje, materia prima dotada de un escaso valor añadido. Se trata de un tipo de productos poco exigentes en estándares de accesibilidad territorial, etc. El único segmento que rompe con la tendencia descrita es el referido al tráfico de automóviles. Este patrón de transporte se repite para todos los registros ferroviarios en Galicia y España.

Entre los campos referidos a las mercancías movilizadas por el ferrocarril español apreciamos como en la tabulación de los registros por parte del Departamento de Informática de RENFE se han producido varios cambios en la metodología. Así, apreciamos que existen tráficos de mercancías que se mantienen durante un reducido número de ejercicios. Por su parte, se aprecia como han aparecido otros nuevos. No se trata tanto de un producto de nueva movilización como de uno que anteriormente estaba cuantificado en términos agregados: es el caso de los cementos y las calizas. Por otro lado, se aprecia como en la serie estadística confeccionada aparecen las maderas en un momento concreto y se consolidan para la mayor parte de la serie. Por último, al ir perfeccionándose el tratamiento estadístico descubrimos como el Departamento de Informática de RENFE opta por desagregar los tráficos de vehículos militares de los de automóviles. Asimismo, en el último de

2 RENFE. 100 Datos Estadísticos (Varios años). Edit. RENFE. Madrid. Cabe apuntar, como se explicita en el pie de las notas de la tabla, que la elaboración de los registros estadísticos en el 2000 no está a cargo del Departamento de Informática de la compañía RENFE. En esta ocasión el origen de los registros corre a cargo del Departamento de Comunicación Corporativa y Relaciones Externas. 
los registros consignados en la serie, ejercicio de 2000, aparecen dos novedades al tabular los valores. En primer lugar, se consignan tráficos internacionales y otros. En segundo lugar, la cuantificación de los registros ya no está a cargo del Departamento de Informática, si no de la Dirección de Comunicación Corporativa y Relaciones Externas.

La tendencia seguida por el tráfico ferroviario español de mercancías nos permitirá establecer comparaciones con el de las provincias gallegas y el conjunto español. Para empezar, podremos analizar si en Galicia y España el ferrocarril ha experimentado una tendencia expansiva en captación de cuota de mercado o, por el contrario, si conoce una pérdida de vitalidad en el valor de los tráficos de mercancías. La serie española nos aclara esto último: claro retroceso de tráfico de mercancías movilizado por el tren. Por otro lado, podemos conocer con precisión cuáles son los segmentos que totalizan los más elevados valores en el ranking y su tendencia en el conjunto de la serie.

\begin{tabular}{|c|c|c|c|c|c|c|c|}
\hline \multicolumn{8}{|c|}{$\begin{array}{l}\text { Tabla n 2.4. Evolución de los principales tráficos ferroviarios nacionales de mercancías } \\
\text { efectuados en vagón completo según la composición de las cargas correspondientes al } \\
\text { período 1975-1998.(Valores en miles de Tn). }\end{array}$} \\
\hline Mercancías. & 1975 & 1980 & 1985 & 1990 & 1995 & 1998 & 2000 \\
\hline Cereal & 1.374 & 1.419 & 2.024 & 1.201 & 1.178 & 1.146 & 1.176 \\
\hline Remolacha & 503 & $1.911^{1}$ & -- & -- & -- & -- & -- \\
\hline Maderas & -- & -- & 690 & 623 & 594 & 580 & 678 \\
\hline Carb.miner. & 2.944 & 2.984 & 2.597 & 2.190 & 2.295 & 1.978 & 2.015 \\
\hline Cementos & 4.357 & 4.065 & 2.8673 & $2.62^{3}$ & 1.828 & 1.953 & 1.792 \\
\hline Minerales & 7.411 & 7.229 & 5.270 & 2.495 & 1.976 & 135 & 137 \\
\hline Prod.sider. & 3.010 & 2.254 & 2.846 & 3.008 & 3.103 & 3.361 & 3.397 \\
\hline Com.líquid. & 7.365 & 5.975 & 1.739 & 1.650 & 537 & 697 & 801 \\
\hline Prod.quími. & 355 & 624 & 971 & 1.012 & 640 & 691 & 623 \\
\hline Buta.y prop. & 524 & 609 & 506 & 723 & 543 & 699 & 674 \\
\hline Abonos & 1.330 & 1.286 & 1.248 & 717 & 417 & 500 & 427 \\
\hline Automóvil & 385 & 425 & 494 & 501 & 460 & 776 & 700 \\
\hline Automóvil militar & -- & 1592 & 157 & 135 & 24 & 38 & 39 \\
\hline Iberiatarifa & 1.091 & 1.013 & 671 & 202 & 75 & 738 & 2.102 \\
\hline Total & 30.649 & 29.953 & 21.923 & 16.943 & 13.646 & 13.254 & 14.5614 \\
\hline
\end{tabular}

Fuente: Departamento de Informática. RENFE. 100 datos estadísticos. Elaboración propia.

(1) A partir de 1979-1980 no se consigna en la fuente 100 datos estadísticos 1979-80-81 las mercancías correspondientes a remolacha. Para no romper la serie hemos tenido que buscar el registro interno de 
este valor que ostentaba el Departamento de Informática. En el lugar de remolacha se pasa a cuantificar las maderas. Este registro no existía en la publicación de 100 datos estadísticos 1975-76-77.

(2) Aparecen desagregados los transportes militares desde 1985. En 1979 en el apartado automóviles aparecen consignados los valores correspondientes a vehículos militares y automóviles. No se especificaba cada partida por separado.

(3) A partir de 1982 se consigna en la misma fila el transporte de cemento y calizas. En el ejercicio de 1987 el Departamento de Informática desagrega en dos filas diferentes estos productos.

(4) En el registro de 2000 aparecen consignados los tráficos internacionales y otros. Estos últimos son un registro nuevo. Por otro lado, la publicación de las estadísticas de transporte ferroviario no lo efectúa el anterior Departamento de Informática. A partir de este período esta actividad corre a cargo de la Dirección de Comunicación Corporativa y Relaciones Externas.

Las principales mercancías que recurren al ferrocarril para cubrir sus desplazamientos son, por este orden, los minerales, los carbones minerales, los combustibles líquidos, los productos siderúrgicos, los productos agrarios (cereal), e iberiatarifa, los abonos y los automóviles. Ahora bien, si se examina con detalle la evolución de estos productos se advierten tres tendencias claras. En primer lugar, existe un grupo de ellos que ha experimentado una pérdida clara de volumen de las mercancías movilizadas: los minerales, el combustible líquido, los productos agrarios y los cementos. En segundo lugar, detectamos otro grupo de productos que se ha mantenido relativamente estable con débiles oscilaciones a la baja y de subida en el conjunto del período: carbón mineral, maderas, butanos y propanos, y los productos siderúrgicos. En tercer lugar, existe un conjunto de bienes que han ido incrementando el valor del tonelaje movilizado para toda la serie temporal: iberiatarifa, automóviles.

Por lo que confiere al perfil que evidencia la matriz de viaje O-D de los tipos de productos llegados o salidos de cada una de las provincias de Galicia, cabe empezar el comentario con dos notas. La primera nos recuerda lo anotado a los pies de página de las tablas. En efecto, la Dirección de informática RENFE no había realizado la computación de los principales productos movilizados por provincia hasta el año 1996. La segunda nos aclara que los registros internos de la UNE Regionales RENFE no se hacían públicos los valores. Los mismos fueron construidos en términos agregados y se consignaba la cifra de totales de Galicia. Por otro lado, a partir de 1991 disponemos de registros para los flujos ferroviarios de Galicia. Estos valores, como hemos indicado, se efectuaban para las principales estaciones y se publicaban en totales. En las tablas no 2.4 y 2.5 tenemos la oportunidad de conocer con detalle cuáles eran las principales mercancías que salían o entraban en Galicia. El estudio del tipo de mercancías movilizadas por tren con matriz de viaje O-D fijado en las provincias gallegas revela cuatro cuestiones de interés:

a) Los tráficos ferroviarios de mercancías con extremo de viaje en Galicia presentan un claro paralelismo con el transporte español de mercancías. 
b) Los principales tráficos movilizados pertenecen a un segmento que tiene por características principales, salvo el de automóviles, a los siguientes trazos. Se trata de mercancías muy voluminosas, muy pesadas, preferencialmente materia prima en bruto o con un escaso nivel de transformación final. Se trata de mercancías de poco valor añadido al comercializarse en los mercados salvo los tráficos de automóviles.

c) Los tráficos movilizados hacia o desde las terminales gallegas presentan como perfil tipo más significativo el ser unos productos poco exigentes en niveles de accesibilidad territorial.

d) El volumen de las mercancías llegadas o salidas de Galicia responden a dos trazos fundamentales. En primer lugar, se trata de una parte de la producción final gallega que se destina bien hacia el mercado interior español, hacia los mercados internacionales o hacia el mercado intrarregional (madera, piedra, cementos, arenas, gravas, automóviles, etc.). El segundo de los rasgos nos explica que Galicia es una puerta de entrada o salida de las mercancías producidas en las CC.AA. que ostentan una dotación de conectividad adecuada. Se trata de tráficos de tránsito que se destinan hacia las principales terminales portuarias como paso previo a su canalización hacia el mercado exterior. En paralelo, existe un porcentaje de mercancías que tienen como destino a Galicia que se orientan a nutrir el sistema productivo gallego.

Por otra parte, las cifras glosadas en la tabla $n^{\circ} 2.4$ nos muestran con total detalle cuál es la intensidad de los tráficos ferroviarios registrados en el conjunto de los tramos de la Gerencia del Eje del Noroeste. Se ha realizado un esfuerzo por desagregar el valor de los tráficos ferroviarios en cada uno de los tramos. Los valores alcanzados nos explican el comportamiento de siete magnitudes:

a) La longitud de viaje O-D de las relaciones gestionadas por la Gerencia del Eje del Noroeste.

b) El valor del número de trenes-km efectuados en los tramos para el segmento de viajeros y mercancías.

c) La densidad media de circulación por kilómetro y día correspondiente a los tráficos de viajeros y mercancías.

d) El valor de las Toneladas Brutas Kilómetro Remolcadas (T.B.K.R.), correspondientes a cada tramo del Eje del Noroeste.

e) El total de las Toneladas-kilómetro netas (Tn-km netas.) movilizadas en cada itinerario del Eje del Noroeste.

f) El nivel de la densidad de carga transportada por kilómetro y día.

g) La densidad de remolque por kilómetro y día. 


\begin{tabular}{|c|c|c|c|c|c|c|}
\hline \multicolumn{7}{|c|}{$\begin{array}{l}\text { Tabla } n^{\circ} 2.5 \text {. Cuadro de resultados de la operatividad del transporte ferroviario correspon- } \\
\text { diente a los trayectos desarrollados por RENFE en la Gerencia del Eje Noroeste. } 1991 \text {. }\end{array}$} \\
\hline \multicolumn{3}{|c|}{ Trayectos gerencia NW. } & \multicolumn{2}{|c|}{ Trenes-Km. (miles) } & \multicolumn{2}{|c|}{$\begin{array}{l}\text { Densidad media de } \\
\text { circulación (por km y día) }\end{array}$} \\
\hline Denominación & Número & Kilómetros & Viajeros & Mercancías & Viajeros & Mercancías \\
\hline Palencia-León & 150 & 122 & $1.670,9$ & $1.322,5$ & 37,5 & 29,7 \\
\hline León-Ujo & 151 & 115 & 932,1 & 729,7 & 22,2 & 17,4 \\
\hline Ujo-Lugo de llanera & 152 & 34 & $1.061,2$ & 179,6 & 85,5 & 14,5 \\
\hline Lugo de Llanera-Gijón & 153 & 22 & 574,5 & 63,6 & 71,5 & 7,9 \\
\hline Soto de Rey-El Entrego & 160 & 22 & 183,0 & 26,6 & 22,8 & 3,3 \\
\hline $\begin{array}{l}\text { Tudela Veguín-Lugo de } \\
\text { Llanera }\end{array}$ & 161 & 14 &, $8 *$ & 48,3 &, $2^{*}$ & 9,5 \\
\hline Oviedo-Trubia & 162 & 13 & 109,8 & $4^{*}$ & 23,1 &, $1^{*}$ \\
\hline Lugo Llanera-Nubledo & 163 & 11 & 10,1 & 63,6 & 2,5 & 15,8 \\
\hline Nubledo-San Juan de Nieva & 164 & 10 & 333,7 & 9,7 & 91,4 & 2,7 \\
\hline Nubledo-Trasona & 165 & 6 &, $0 *$ & 20,7 &, $0^{*}$ & 9,5 \\
\hline Veriña-Abońo & 166 & 2 &, $1^{*}$ & 5,2 &, $1^{*}$ & 7,1 \\
\hline León-Astorga & 200 & 52 & 415,0 & 383,1 & 21,9 & 20,2 \\
\hline Astorga-Ponferrada & 201 & 77 & 580,7 & 557,9 & 20,7 & 19,9 \\
\hline $\begin{array}{l}\text { Ponferrada-Monforte de } \\
\text { Lemos }\end{array}$ & 202 & 110 & 776,5 & 854,1 & 19,3 & 21,3 \\
\hline Monforte-Betanzos Infesta & 203 & 163 & 883,9 & 503,2 & 14,9 & 8,5 \\
\hline $\begin{array}{c}\text { Betanzos Infesta-A Coruńa } \\
\text { San Diego }\end{array}$ & 204 & 23 & 163,7 & 53,5 & 19,5 & 6,4 \\
\hline $\begin{array}{c}\text { Bifurc. El Burgo A Coruña- } \\
\text { San Critóbal }\end{array}$ & 205 & 5 & 38,7 & 6,7 & 21,2 & 3,7 \\
\hline $\begin{array}{c}\text { Toral de Vados-Villafranca } \\
\text { del Bierzo }\end{array}$ & 206 & 9 &, $3 *$ & 4,8 &, $1^{*}$ & 1,5 \\
\hline Betanzos Infesta-Ferrol & 210 & 43 & 254,7 & 28,0 & 16,2 & 1,8 \\
\hline $\begin{array}{l}\text { Monforte de Lemos- } \\
\text { Ourense Empalme }\end{array}$ & 220 & 45 & 346,6 & 280,4 & 21,1 & 17,7 \\
\hline Ourense Empalme-Guillarei & 221 & 95 & 639,3 & 517,7 & 18,4 & 14,9 \\
\hline Guillarei-Redondela & 222 & 25 & 170,8 & 126,7 & 18,7 & 13,9 \\
\hline Redondela-Vigo & 223 & 12 & 231,0 & 53,3 & 52,7 & 12,2 \\
\hline Guillarei-Valença do Minho & 224 & 6 &, $6^{*}$ & 3,5 &, $3 *$ & 1,6 \\
\hline Redondela-Santiago & 230 & 91 & 789,3 & 77,7 & 23,8 & 2,3 \\
\hline Ourense Empalme-Santiago & 313 & 130 & 657,5 & 298,7 & 13,9 & 6,3 \\
\hline $\begin{array}{l}\text { Santiago-A Coruña San } \\
\text { Cristóbal }\end{array}$ & 314 & 75 & 619,1 & 75,1 & 22,6 & 2,7 \\
\hline Total & & & $11.443,9$ & $6.304,3$ & 23,5 & 13,0 \\
\hline
\end{tabular}

Fuente: RENFE. Dirección de Informática. Elaboración Propia.

(*) La fuente estadística manejada por la Dirección de Informática de RENFE ha computado en el registro la parte decimal y no la parte entera. Por ello, debemos pensar que la parte entera es cero (0). 


\begin{tabular}{|c|c|c|c|c|c|c|}
\hline \multicolumn{7}{|c|}{$\begin{array}{c}\text { Tabla } n^{\circ} 2.5 \text {. (Continuación). Cuadro de resultados de la operatividad del transporte } \\
\text { ferroviario correspondiente a los trayectos desarrollados por RENFE en la Gerencia del Eje } \\
\text { Noroeste. } 1991 .\end{array}$} \\
\hline Trayectos Gerencia NW. & $\begin{array}{c}\text { Tn-km } \\
\text { Netas }\left(10^{6}\right) \\
\end{array}$ & \begin{tabular}{|c|}
$\begin{array}{c}\text { Densidad de } \\
\text { carga ( } \mathrm{km} / \mathrm{d} \text { á) }\end{array}$ \\
\end{tabular} & T.K.B.R. & (Millones) & $\begin{array}{r}\begin{array}{r}\text { Densidad } \\
\text { (por }\end{array} \\
\end{array}$ & $\begin{array}{l}\text { de remolque } \\
\text { m y día) }\end{array}$ \\
\hline Denominación & Mercancías & Kilómetros & Viajeros & Mercancías & Viajeros & Mercancías \\
\hline Palencia-León & 402,0 & $9.027,6$ & 442,2 & 875,2 & $9.930,4$ & $19.654,2$ \\
\hline León-Ujo & 223,0 & $5.312,7$ & 191,4 & 473,0 & $4.559,9$ & $11.268,6$ \\
\hline Ujo-Lugo de llanera & 58,5 & $4.713,9$ & 153,6 & 117,8 & $12.377,1$ & $9.492,3$ \\
\hline Lugo de Llanera-Gijón & 17,7 & $2.204,2$ & 83,6 & 38,5 & $10.411,0$ & $4.794,5$ \\
\hline Soto de Rey-El Entrego & 5,5 & 684,9 & 21,8 & 14,3 & $2.714,8$ & $1.780,8$ \\
\hline $\begin{array}{c}\text { Tudela Veguín-Lugo de } \\
\text { Llanera } \\
\end{array}$ & 10,9 & $2.133,1$ &, $1^{*}$ & 27,3 & 19,6 & $5.342,5$ \\
\hline Oviedo-Trubia &, $0^{*}$ & 0 & 14,2 &, $1^{*}$ & $2.992,6$ & 21,1 \\
\hline Lugo Llanera-Nubledo & 20,7 & $5.155,7$ & 1,8 & 43,0 & 448,3 & $10.709,8$ \\
\hline Nubledo-San Juan de Nieva & 2,2 & 602,7 & 44,1 & 5,0 & $12.082,2$ & $1.369,9$ \\
\hline Nubledo-Trasona & 7,3 & $3.333,3$ &, $0 *$ & 15,0 &, $0 *$ & $6.849,3$ \\
\hline Veriña-Aboño & 1,5 & $2.054,8$ &, $0 *$ & 3,3 &, $0 *$ & $4.520,5$ \\
\hline León-Astorga & 73,2 & $3.856,7$ & 119,5 & 180,4 & $6.296,1$ & $9.504,7$ \\
\hline Astorga-Ponferrada & 106,6 & $3.792,9$ & 168,5 & 261,2 & $5.995,4$ & $9.293,7$ \\
\hline $\begin{array}{l}\text { Ponferrada-Monforte de } \\
\text { Lemos }\end{array}$ & 179,5 & $4.470,7$ & 233,8 & 428,7 & $5.823,2$ & $10.677,5$ \\
\hline $\begin{array}{l}\text { Monforte-Betanzos } \\
\text { Infesta }\end{array}$ & 87,6 & $1.472,4$ & 210,1 & 210,2 & $3.531,4$ & $3.533,1$ \\
\hline $\begin{array}{c}\text { Betanzos Infesta-A Coruña } \\
\text { San Diego }\end{array}$ & 9,3 & $1.07,8$ & 31,3 & 23,0 & $3.728,4$ & $2.739,7$ \\
\hline $\begin{array}{c}\text { Bifurc. El Burgo A Coruña- } \\
\text { San Critóbal }\end{array}$ & ,9* & 493,2 & 7,4 & 2,2 & $4.054,8$ & $1.205,5$ \\
\hline $\begin{array}{c}\text { Toral de Vados-Villafranca } \\
\text { del Bierzo }\end{array}$ & 1,5 & 456,6 &, $0^{*}$ & 2,8 &, $0 *$ & 852,4 \\
\hline Betanzos Infesta-Ferrol & 3,6 & 229,4 & 47,2 & 8,8 & $3.007,3$ & 560,7 \\
\hline $\begin{array}{c}\text { Monforte de Lemos- } \\
\text { Ourense Empalme }\end{array}$ & 58,7 & $3.573,8$ & 74,8 & 135,6 & $4.554,0$ & $8.255,7$ \\
\hline $\begin{array}{c}\text { Ourense Empalme- } \\
\text { Guillarei }\end{array}$ & 84,5 & $2.436,9$ & 170,2 & 211,7 & $4.908,4$ & $6.105,3$ \\
\hline Guillarei-Redondela. & 19,9 & $2.180,8$ & 45,2 & 50,3 & $4.953,4$ & $5.512,3$ \\
\hline Redondela-Vigo & 6,8 & $1.552,5$ & 46,6 & 18,5 & $10.639,3$ & $4.223,7$ \\
\hline Guillarei-Valença do Minho. &, $3^{*}$ & 137,0 &, $1^{*}$ & $9 *$ & 45,7 & 411,0 \\
\hline Redondela-Santiago & 10,7 & 322,1 & 145,6 & 26,1 & $4.383,6$ & 785,8 \\
\hline $\begin{array}{c}\text { Ourense Empalme- } \\
\text { Santiago }\end{array}$ & 58,1 & $1.224,4$ & 154,2 & 122,4 & $3.249,7$ & $2.579,6$ \\
\hline $\begin{array}{c}\text { Santiago-A Coruña San } \\
\text { Cristóbal }\end{array}$ & 12,4 & 453,0 & 138,2 & 27,5 & $5.048,4$ & $1.004,6$ \\
\hline Total. & $1.462,9$ & $3.009,0$ & $2.545,5$ & $3.322,8$ & $5.235,7$ & $6.834,5$ \\
\hline
\end{tabular}

Fuente: RENFE. Dirección de Informática. Elaboración propia.

(*) La fuente estadística manejada por la Dirección de Informática de RENFE ha computado en el registro la parte decimal y no la parte entera. Por ello, debemos pensar que la parte entera es cero (0). 
La tabla $n^{\circ} 2.5$ se complementa con la construcción de los valores de la n ${ }^{\circ} 2.6$. En esta ocasión hemos practicado un filtrado a las magnitudes computadas y a los tramos de la Gerencia del Eje del Noroeste. Nótese como en la elaboración de la tabla únicamente se han consignado los registros correspondientes a los tramos ferroviarios de Galicia. En paralelo, y como en esta sección nos estamos ocupando del comentario de los tráficos de mercancías, se han tabulado únicamente los flujos de mercancías generados o atraídos en cada tramo. El resultado de la modificación de la $n^{\circ} 2.4$ es la ganancia en nivel de sencillez y concreción en el contenido de la información. Si nos centramos en los valores del tráfico de mercancías movilizado por tren destacaremos la importancia de los tramos: Ponferrada-Monforte de Lemos, Monforte de Lemos-Empalme Ourense, Ourense Empalme-Guillarei, Guillarei-Redondela y Ourense Empalme-Santiago.

\begin{tabular}{|c|c|c|c|c|}
\hline \multicolumn{5}{|c|}{$\begin{array}{c}\text { Tabla } \mathrm{n}^{\circ} \text { 2.6. Cuadro de resultados de la operatividad del transporte ferroviario } \\
\text { correspondiente a los trayectos desarrollados por RENFE en la Gerencia del Eje Noroeste. } \\
\text { Tramos gallegos. } 1991 \text {. }\end{array}$} \\
\hline \multicolumn{3}{|c|}{ Trayectos gerencia NW. } & $\begin{array}{l}\text { Trenes-Km. } \\
\text { (miles) }\end{array}$ & $\begin{array}{c}\text { Densidad media de } \\
\text { circulación (km y día) }\end{array}$ \\
\hline Denominación & Número & Kilómetros & Mercancías & Mercancías \\
\hline Ponferrada-Monforte de Lemos & 202 & 110 & 854,1 & 21,3 \\
\hline Monforte-Betanzos Infesta & 203 & 163 & 503,2 & 8,5 \\
\hline Betanzos Infesta-A Coruña San Diego & 204 & 23 & 53,5 & 6,4 \\
\hline Bifurc. El Burgo A Coruña-San Cristóbal & 205 & 5 & 6,7 & 3,7 \\
\hline Toral de Vados-Villafranca del Bierzo & 206 & 9 & 4,8 & 1,5 \\
\hline Betanzos Infesta-Ferrol & 210 & 43 & 28,0 & 1,8 \\
\hline Monforte de Lemos-Ourense Empalme & 220 & 45 & 280,4 & 17,7 \\
\hline Ourense Empalme-Guillarei & 221 & 95 & 517,7 & 14,9 \\
\hline Guillarei-Redondela & 222 & 25 & 126,7 & 13,9 \\
\hline Redondela-Vigo & 223 & 12 & 53,3 & 12,2 \\
\hline Guillarei-Valença do Minho & 224 & 6 & 3,5 & 1,6 \\
\hline Redondela-Santiago & 230 & 91 & 77,7 & 2,3 \\
\hline Ourense Empalme-Santiago & 313 & 130 & 298,7 & 6,3 \\
\hline Santiago-A Coruña San Cristóbal & 314 & 75 & 75,1 & 2,7 \\
\hline Total & & & $6.304,3$ & 13,0 \\
\hline
\end{tabular}

Fuente: RENFE. Dirección de Informática. Elaboración Propia.

${ }^{(*)}$ La fuente estadística manejada por la Dirección de Informática de RENFE ha computado en el registro la parte decimal y no la parte entera. Por ello, debemos pensar que la parte entera es cero (0). 


\begin{tabular}{|c|c|c|c|c|}
\hline \multicolumn{5}{|c|}{$\begin{array}{c}\text { Tabla } n^{\circ} 2.6 \text {. (Continuación). Cuadro de resultados de la operatividad del transporte } \\
\text { ferroviario correspondiente a los trayectos desarrollados por RENFE en la Gerencia del Eje } \\
\text { Noroeste. Tramos gallegos. } 1991 .\end{array}$} \\
\hline Trayectos Gerencia NW. & $\begin{array}{l}\text { Tn-km Netas } \\
\left(10^{6}\right)\end{array}$ & $\begin{array}{l}\text { Densidad de carga } \\
\text { (por km/día) }\end{array}$ & T.K.B.R. & $\begin{array}{l}\text { Densidad de } \\
\text { remolque } \\
\text { (por km y día) }\end{array}$ \\
\hline Denominación & Mercancías & Kilómetros & Mercancías & Mercancías \\
\hline Ponferrada-Monforte de Lemos & 179,5 & $4.470,7$ & 428,7 & $10.677,5$ \\
\hline Monforte-Betanzos Infesta & 87,6 & $1.472,4$ & 210,2 & $3.533,1$ \\
\hline $\begin{array}{c}\text { Betanzos Infesta-A Coruña San } \\
\text { Diego }\end{array}$ & 9,3 & $1.07,8$ & 23,0 & $2.739,7$ \\
\hline $\begin{array}{l}\text { Bifurc. El Burgo A Coruña-San } \\
\text { Cristóbal }\end{array}$ & $9 *$ & 493,2 & 2,2 & $1.205,5$ \\
\hline $\begin{array}{c}\text { Toral de Vados-Villafranca del } \\
\text { Bierzo }\end{array}$ & 1,5 & 456,6 & 2,8 & 852,4 \\
\hline Betanzos Infesta-Ferrol & 3,6 & 229,4 & 8,8 & 560,7 \\
\hline $\begin{array}{c}\text { Monforte de Lemos-Ourense } \\
\text { Empalme }\end{array}$ & 58,7 & $3.573,8$ & 135,6 & $8.255,7$ \\
\hline Ourense Empalme-Guillarei & 84,5 & $2.436,9$ & 211,7 & $6.105,3$ \\
\hline Guillarei-Redondela & 19,9 & $2.180,8$ & 50,3 & $5.512,3$ \\
\hline Redondela-Vigo & 6,8 & $1.552,5$ & 18,5 & $4.223,7$ \\
\hline Guillarei-Valença do Minho &, $3^{*}$ & 137,0 & ,9* & 411,0 \\
\hline Redondela-Santiago & 10,7 & 322,1 & 26,1 & 785,8 \\
\hline Ourense Empalme-Santiago & 58,1 & $1.224,4$ & 122,4 & $2.579,6$ \\
\hline $\begin{array}{c}\text { Santiago-A Coruña San } \\
\text { Cristóbal }\end{array}$ & 12,4 & 453,0 & 27,5 & $1.004,6$ \\
\hline Total & $1.462,9$ & $3.009,0$ & $3.322,8$ & $6.834,5$ \\
\hline
\end{tabular}

Fuente: RENFE. Dirección de Informática. Elaboración propia.

(*) La fuente estadística manejada por la Dirección de Informática de RENFE ha computado en el registro la parte decimal y no la parte entera. Por ello, debemos pensar que la parte entera es cero (0).

No obstante, los valores totalizados por los tramos gallegos no resultan equiparables a los alcanzados por otras relaciones en la Gerencia del Eje del Noroeste en: Palencia-León, León-Ujo, Ujo-Lugo de Llanera. La desigual movilización de mercancías en el conjunto de los tramos del Eje del Noroeste explica como las mayores densidades se localizan entre León-Palencia y Asturias. 


\section{La especialización de la UNE Cargas para corregir la pérdida de cuota de mercado}

El estudio de los volúmenes de mercancías movilizadas por ferrocarril en las estaciones gallegas nos deja a luz la existencia de un conjunto de problemas que está padeciendo el transporte ferroviario en Galicia. Para empezar, la evolución de los niveles de la demanda de desplazamiento ha experimentado una profunda regresión en sus tonelajes. Al examinar las principales relaciones ferroviarias de la matriz de viaje O-D apreciamos un hecho subrayable. En efecto, los valores de las mercancías ferroviarias movilizadas a escala de las provincias de Galicia respecto de las CC.AA. españolas han sufrido una notable pérdida de relaciones. Así, no sólo se ha producido una caída en el cómputo de los tonelajes movilizados, si no que también se ha producido una pérdida de tráficos con numerosas provincias españolas. Este hecho aún es más relevante si desagregamos la información de los tráficos ferroviarios a nivel de cada una de las principales estaciones ferroviarias gallegas que registran movimientos de mercancías. La presencia de esta situación nos indica tres escenarios posibles como factores justificantes:

1) La modernización infraestructural practicada en la malla viaria española ha originado una verdadera lateralización de los tráficos españoles de mercancías en beneficio de la carretera.

2) La concurrencia del ferrocarril en el mercado del transporte español y gallego ha puesto de relieve una situación de dualidad operativa entre la carretera y el tren. Mientras el primer modo ha logrado incrementar ostensiblemente sus estándares de calidad para la demanda potencial de viaje, el ferrocarril se ha quedado sumido en una situación de anquilosamiento y de pérdida de competitividad real.

3) La demanda de transporte comienza a priorizar sus opciones de movilización de las cargas a favor del transporte por carretera. ${ }^{3}$ Por su parte, el ferrocarril en los últimos años del decenio de 1990 confirma la crítica situación

3 Cabe destacar que en los modelos de planificación de los parques empresariales y polígonos industriales cada vez cobra mayor protagonismo la articulación de estos centros productivos respecto de una infraestructura viaria dotada de elevada capacidad. Por el contrario, existen numerosos polígonos industriales que no se encuentran articulados por medio del ferrocarril. En los últimos tiempos de la política autonómica de polígonos industriales y parques empresariales se ha priorizado la articulación del centro productivo en base a la conexión con carreteras dotadas de doble carril por sentido del tráfico. Por su parte, se ha marginado de manera importante las oportunidades que para el movimiento de mercancías le brindaría el ferrocarril. Esta asimetría en cuanto a oferta de conectividad supone un factor de ventaja para la carretera en detrimento del tren. 
que venía arrastrando desde los años 1980: pérdida de tráficos tradicionales

(cementos, material de construcción, granito, maderas, automóviles, etc.).

La caída de los registros de las mercancías movilizadas por vía ferroviaria en Galicia también ha sido debida a la escasa aplicación de las medidas de planificación ferroviaria diseñadas por RENFE. En efecto, los trenes de mercancías comienzan a especializar la movilización de sus tráficos por medio del uso del contenedor. Así, se produce la constitución de la red Intercontainer. Este hito dio lugar a que en Julio de 1972 se produjese la primera expedición de trenes TECO (Tren Expreso de Contenedores) desde la estación de Madrid-Peñuelas. ${ }^{4}$ Este hecho supuso la conformación de la red TECO, que pasó a quedar estructurada en el año 1976 al comunicar las fachadas marítimas peninsulares. La importancia de la red TECO es clara. Por medio de esta malla ferroviaria se lograba articular un importante conjunto de nudos ferroviarios entre sí en base a la operatividad de unos trenes de contenedores. Se trataba ahora de una oferta de servicio exclusiva para este tipo de embalajes. La respuesta territorial y operativa que conoció la comercialización de los trenes TECO fue muy importante. A modo de ejemplo, cabe destacar que en el año 1976 la oferta de servicio TECO totalizaba un total de 24 trenes diarios, asî como unos 22 trenes cliente semanales. ${ }^{5}$ Así, la malla diseñada posibilitaba una efectiva oferta de servicio regular semejante a la de los trenes de viajeros. Desde el prisma organizativo, se produjo un conjunto de mejoras en la estructura operativa del transporte ferroviario español. De este modo, el transporte combinado pasaba a depender de la división comercial de RENFE. En el año 1979 se había producido otro factor destacable: la creación del ATIMER (Autónoma de Transportes Inter-

4 En el año 1972 únicamente se logró poner en servicio un total de dos trenes TECO diarios entre Madrid y Barcelona (uno por cada sentido del tráfico). La capacidad de carga del convoy era muy reducida, toda vez que los trenes que funcionaban para esta relación movilizaban únicamente 36 contenedores por expedición. Por tanto, la oferta de servicio no llegaba a dar cobertura a la generación de flujos en las diferentes regiones españolas, existiendo una importante demanda no atendida.

5 Las expectativas de crecimiento en cuanto a captación de clientes eran claramente positivas. Así, la política comercial de la compañía impulsó la elaboración del primer Plan de Containerización 1972-1975. Este modelo de planificación experimentó una ampliación temporal, en base a la incorporación de nuevas medidas de planificación, que le permitieron llegar hasta el año 1978. Los principales objetivos del Plan de Containerización son básicamente cuatro:

a) Establecer una red TECO.

b) Impulsar la conversión de aquellas estaciones en las cuales se prestaba servicio de transporte combinado.

c) Tratar de disponer una suficiente dotación de contenedores para garantizar la prestación de servicio según el número de expediciones y las relaciones territoriales principales. Para ello, había que adaptar la dotación de vagones a la capacidad de carga de los trenes y al volumen de mercancías generado. 
modales de Mercancías RENFE), ${ }^{6}$ bajo los objetivos del Plan de Actuación Urgente. ${ }^{7}$ Este órgano se encargaría de la gestión de los tráficos "puerta a puerta." En último lugar, las medidas correctoras asignadas al transporte de mercancías dieron lugar a que se constituyera la Unidad de Negocio Transporte Combinado en 1993. Se le dotaba así a este tipo de tráficos los mecanismos oportunos para gestionar un tipo de mercancías que tenía unas características propias y diferenciadas. Este avance dio origen a que este tipo de tráficos se constituyeran en Unidades de Transporte Intermodal (UTI).

La política comercial de la compañía RENFE aún pretendía especializar más al ferrocarril para introducirlo en un mercado muy competitivo. Así, la comercialización de los trenes TECO supuso que la compañía RENFE lograra introducir en el mercado del transporte un producto ferroviario crecientemente especializado a cada segmento del mercado. El objetivo fijado era claro. Se trataba ahora de fomentar la adaptación de la oferta de transporte ferroviario al perfil de las grandes y pequeñas empresas. La operatividad ferroviaria posibilitaba la expedición, por igual, tanto de un único contenedor como de un tren completo a cualquier lugar del territorio español en unos plazos comprendidos entre las $8 \mathrm{y}$ las 12 horas. Este hecho dio lugar a que al modelo del Tren TECO se le incorporasen nuevos productos. El ejemplo más destacado lo constituye, precisamente, el Tren PUERTO. La oferta de este nuevo producto tenía por objetivo impulsar la conexión de las terminales marítimas entre sí respecto de las terminales de transporte combinado. Las mercancías movilizadas por contenedor en los Trenes PUERTO tenían usualmente como matriz O-D a los buques. Por tanto, este tipo de tráficos representaban en buena medida a un importante segmento de las mercancías movilizadas por el comercio exterior: flujos de mercancías de exportación e importación.

Ahora bien, la oferta de este atractivo producto para la captación de tráficos no se produjo en Galicia. La comercialización del Tren PUERTO se había hecho efectiva en los principales puertos españoles: Algeciras, Valencia, Barcelona, Cá-

6 La planificación de la red TECO dio lugar a que Galicia contase con dos estaciones especializadas en este tipo de tráficos: A Coruña San Diego y Vigo Guixar. La malla española queda constituida por 35 estaciones. De las mismas las que totalizan los mayores volúmenes de mercancías movilizadas son, por este mismo orden, las siguientes: Barcelona-Morrot, Silla y Madrid-Abroñigal.

$7 \mathrm{Al}$ examinar los objetivos y actuaciones principales asignadas al Plan Containerización y al Tren TECO apreciamos como Galicia había quedado fuera de las prioridades de prestación de servicio a cargo de este atractivo producto ferroviario. Una vez que en el año 1972 se ponía en funcionamiento la primera oferta de servicio TECO, en 1973 se comercializaba por Tren TECO las relaciones Bilbao-Parque e Irún a la malla diseñada inicialmente. Posteriormente se constituía la gran terminal Madrid-Abroñigal, siendo una de las principales terminales españolas que prestaba servicio al transporte intermodal. 
diz y Santurce. Como se advierte, eran puertos casi todos ellos del Mediterráneo. La conexión de las terminales portuarias indicadas se realizaba respecto de Madrid. Por otro lado, existían comercializaciones de Tren PUERTO transversales: conexión de Barcelona con Valencia y Santurce (Bilbao). De igual modo, se había impulsado la conexión de Barcelona con Leixoes (Oporto) y Lisboa. Esta oferta de tráfico intermodal posibilitaba la configuración de una red que articulaba a las terminales portuarias del Atlántico, (Santurce, Leixoes y Lisboa), con las mediterráneas.

La especialización del transporte ferroviario orientado a la canalización de mercancías por contenedor conoció en la configuración del servicio EURECO a uno de sus productos estrella. Era este tipo de oferta ferroviaria un tráfico que había derivado de la especialización progresiva del transporte por ferrocarril, así como de las disposiciones normativas en materia de transporte emitidas por la U.E. En esta misma línea, se logró poner en funcionamiento dos últimos productos:

a) El Tren Cliente. Este tipo de tráficos estaba orientado a atender a la demanda de viaje que precisaba de unas condiciones particulares de transporte.

b) El Servicio Domicilio Preferente. Este producto ferroviario se había especializado en la atención individualizada a cada demandante de desplazamiento. El servicio ferroviario Domicilio Preferente aseguraba la entrega de las mercancías en las grandes superficies de Madrid en unos horarios preestablecidos entre las partes. Asimismo, realizaba las tareas de carga/descarga en los muelles, la colocación de los productos en los estantes y, finalmente, incluía la gestión de albaranes. ${ }^{8}$

8 La oferta gallega de servicio quedó al margen de este tipo de mejoras. Los puertos gallegos dejaron de movilizar unos notables tonelajes por el modo ferroviario al no ajustarse las necesidades de la demanda a los patrones de calidad que el tren estaba ofertando en otros lugares del territorio español. Un importante avance en el modelo de gestión del transporte ferroviario no conocido en Galicia fue la aplicación del sistema SACICO (Sistema Informático de Control de Contenedores). Esta herramienta posibilitaba que los clientes de las mercancías conociesen en tiempo real la situación que estaba conociendo sus productos al ser movilizados en la matriz O-D. Por otro lado, este nuevo modelo de gestión lograba corregir los tiempos de demora de las mercancías al ser movilizadas entre extremos de viaje, al tiempo que también se incrementaban los niveles de seguridad del tráfico ferroviario. Dentro del modelo de modernización de la gestión, que tampoco tuvo efectos en el tráfico ferroviario gallego, destacaremos a la puesta en funcionamiento del proyecto informático GOYA (Gestión Operativa y Administración). Este sistema de gestión había sido desarrollado por la propia UNE Transporte Combinado RENFE. El sistema había sido ideado para logar una mejora en el control de las partes operativas y administrativas de las actividades ferroviarias. El avance más destacado en la gestión del tráfico ferroviario de mercancías se logró cuando en 1996 se alcanza la concesión de la norma ISO 9002 para el producto Trenes TECO-PUERTO de las relaciones Santurce-Madrid-Abroñigal. 


\section{La cobertura de servicio mediante la red de terminales de intercambio modal y actividades logísticas en España}

La especialización del transporte ferroviario había sido entendida como la única estrategia de actuación válida para lograr evitar la fuerte caída en el descenso de mercancías movilizadas por el ferrocarril. No obstante, ya indicábamos líneas arriba que Galicia apenas se había visto beneficiada de la modernización en la gestión ferroviaria y de la puesta en servicio de productos muy ajustados a las necesidades reales de la demanda de transporte. En la tabla $n^{\circ} 4.1$ podemos apreciar cómo se estructuraba la oferta territorial de terminales de intercambio modal y actividades logísticas por las CC.AA españolas.

\begin{tabular}{|c|c|c|}
\hline \multicolumn{3}{|c|}{$\begin{array}{l}\text { Tabla } n^{\circ} 4.1 \text {. Distribución territorial de la oferta de terminales de intercambio modal y } \\
\text { actividades logísticas en las CC.AA. según la naturaleza de las estaciones. }\end{array}$} \\
\hline CC.AA. & Localización de la estación & Tipo de terminal de intercambio \\
\hline \multirow{5}{*}{ Galicia. } & A Coruña & Terminal terrestre. \\
\hline & Santiago. & Terminales asimiladas. \\
\hline & Vigo. & Terminal terrestre. \\
\hline & Lugo. & Terminal terrestre. \\
\hline & Lalín & Terminal asimilada. \\
\hline \multirow{2}{*}{ Castilla-León. } & León. & Terminal terrestre. \\
\hline & Valladolid. & Terminales terrestres. \\
\hline \multirow{2}{*}{ Asturias. } & Avilés. & Terminal terrestre. \\
\hline & Viella. & Terminales asociadas. \\
\hline Cantabria. & Torrelavega. & Terminal terrestre. \\
\hline Centro. & Madrid. & Terminal terrestre. \\
\hline Extremadura & Mérida. & Terminal terrestre. \\
\hline Castilla-La Mancha. & Puertollano. & Terminales asociadas. \\
\hline \multirow{9}{*}{ Andalucía. } & Huelva. & Terminal terrestre. \\
\hline & Puerto de Sta. María. & Terminal terrestre. \\
\hline & Cádiz. & Terminales portuarias. \\
\hline & Algeciras. & Terminales portuarias. \\
\hline & San Roque. & Terminal terrestre. \\
\hline & Sevilla. & Terminal terrestre. \\
\hline & Córdoba. & Terminal terrestre. \\
\hline & Málaga. & Terminal terrestre. \\
\hline & L. Baeza. & Terminal terrestre. \\
\hline
\end{tabular}




\begin{tabular}{|c|c|c|}
\hline CC.AA. & Localización de la estación & Tipo de terminal de intercambio \\
\hline \multirow{5}{*}{ Cataluña. } & Barcelona. & $\begin{array}{c}\text { Terminal terrestre. Terminales } \\
\text { portuarias. }\end{array}$ \\
\hline & Tarragona. & Terminal terrestre. \\
\hline & Granollers. & Terminal terrestre. \\
\hline & Lérida. & Terminales terrestres. \\
\hline & Portbou. & Terminales terrestres. \\
\hline \multirow{3}{*}{ Comunidad de Valencia. } & Valencia. & $\begin{array}{l}\text { Terminales terrestres. Terminales } \\
\text { portuarias. }\end{array}$ \\
\hline & Villareal. & Terminales asimiladas. \\
\hline & Alicante. & Terminales terrestres. \\
\hline \multirow{2}{*}{ Murcia. } & Cartagena. & Terminales portuarias. \\
\hline & Murcia. & Terminales terrestres. \\
\hline \multirow{4}{*}{ País Vasco. } & Santurce. & Terminales portuarias. \\
\hline & Vitoria. & Terminales terrestres. \\
\hline & Bilbao. & Terminales terrestres. \\
\hline & Irún. & Terminales terrestres. \\
\hline Navarra. & Pamplona. & Terminales terrestres. \\
\hline Aragón. & Zaragoza. & Terminales terrestres. \\
\hline Illes Baleares. & Mallorca. & Servicio a las islas. \\
\hline
\end{tabular}

Fuente: UNE Transporte Combinado RENFE. Elaboración Propia.

Los datos de la tabla nos muestran como en Galicia no existía ninguna estación portuaria. Este hecho condicionaba el importante volumen de mercancías que podían movilizar las terminales de A Coruña y Vigo. Las principales características operativas que ostentaba la prestación de servicio de la UNE Transporte Combinado RENFE eran:

1) Se posibilitaba la conexión diaria con cualquier punto de España o Europa a través de la intermodalidad ferroviaria/terrestre/marítima. De este modo se lograba la movilización de todo tipo de mercancías: alimentación, componentes de automoción, textil, electrodomésticos, productos químicos, etc., por medio del contenedor.

2) El soporte logístico de la UNE Transporte Combinado RENFE estaba constituido por 70 trenes diarios nacionales, 50 internacionales, 39 terminales ferroviarias, 3.000 contenedores. La operatividad del transporte ferroviario estaba cubierta por la implantación de un sistema informático y una asignación de personal muy cualificado.

3) Se diseñaban productos a medida del consumidor. De este modo se atendía a las necesidades básicas de los clientes potenciales. 
4) Se ofertaba un servicio de transporte ferroviario puerta a puerta sin que el cliente tuviese que manipular las mercancías movilizadas.

5) Las tarifas por prestación de servicio se beneficiaban del modo de pago aplazo y hecho efectivo mediante tarjeta de crédito.

6) Las terminales ferroviarias se ponían totalmente a disposición de la demanda potencial a base de ofrecerle a la misma:

a. Facilidades para el depósito de UTIS (contenedores, cajas móviles, semiremolques, etc.).

b. Oferta de áreas de almacenaje de mercancías para la distribución de los pedidos.

c. Disponibilidad de áreas destinadas a oficinas para desarrollar las actividades logísticas.

d. Oferta de servicios de lavado y reparación de los contenedores.

En las tablas siguientes podemos apreciar cómo se había diseñado la oferta de servicio cubierta por la red TECO y Trenes PUERTO al territorio español. Así, se impulsó una organización interna del servicio Transporte Combinado RENFE en base a la constitución de seis unidades territoriales ferroviarias: Andalucía-Extremadura, Galicia-Asturias-Cantabria, Centro, Cataluña, Levante y País Vasco.

Los datos de la tabla n ${ }^{\circ} 4.2$ muestran la oferta de servicio cubierta por Transporte Combinado RENFE en la unidad territorial Galicia-Asturias-Cantabria. La información de la tabla nos muestra cinco indicadores:

1) La matriz de viaje O-D de cada unidad territorial cubierta por el Transporte Combinado.

2) El total de expediciones diarias que cubren la matriz de viaje.

3) Los intervalos horarios que son necesarios para cubrir cada uno de los trayectos planificados.

4) El total de relaciones territoriales comercializadas por este tipo de tráfico ferroviario.

5) Los centros intercambiadores de mercancías. Se trata de puntos nodales en la red ferroviaria que posibilitan las operaciones de carga y descarga de mercancías en contenedor.

A luz de los valores consignados, apreciamos como las conexiones de Galicia se hacían efectivas mediante tres expediciones regulares: A Coruña San Diego, Lugo y Vigo Guixar. Los itinerarios que cubrían estas relaciones eran básicamente dos: Barcelona-Morrot (cubierta por Vigo Guixar) y Madrid-Abroñigal (cubierta por A Coruña S. D. y Lugo). Si nos centramos en los tiempos de viaje empleados en cubrir los itinerarios fijados apreciamos como van de las 15 h 45 minutos (A Coruña) a las 13 h 35 minutos de Lugo y las 25 h 55 minutos de Vigo Guixar. La matriz nos 
muestra como los días laborales de la semana las estaciones gallegas logran establecer relaciones con las indicadas.

\begin{tabular}{|c|c|c|c|c|c|}
\hline \multicolumn{6}{|c|}{ Tabla $n^{\circ}$ 4.2. Oferta de servicio mediante Transporte Combinado RENFE en la unidad } \\
territorial Galicia-Asturias-Cantabria. \\
\hline Origen & Destino. & $\begin{array}{c}\text { Hora de } \\
\text { salida. }\end{array}$ & $\begin{array}{c}\text { Hora de } \\
\text { Llegada. }\end{array}$ & $\begin{array}{c}\text { Días } \\
\text { circulación. }\end{array}$ & Intervenciones*. \\
\hline $\begin{array}{c}\text { A Coruña } \\
\text { San Diego }\end{array}$ & $\begin{array}{c}\text { Madrid- } \\
\text { Abrońigal }\end{array}$ & $20: 15$ & $11: 30$ & LMXJVS- & $\begin{array}{c}\text { Lalín-Monforte-León } \\
\text { CL. }\end{array}$ \\
\hline $\begin{array}{c}\text { Santander- } \\
\text { Muriedas }\end{array}$ & $\begin{array}{c}\text { Barcelona } \\
\text { Morrot }\end{array}$ & $17: 10$ & $11: 18$ & LMXJV-- & $\begin{array}{c}\text { Torrelavega-CIM } \\
\text { Zaragoza }\end{array}$ \\
\hline $\begin{array}{c}\text { Santander- } \\
\text { Muriedas }\end{array}$ & $\begin{array}{c}\text { Madrid- } \\
\text { Abrońigal }\end{array}$ & $18: 25$ & $03: 35$ & LMJV-- & Torrelavega \\
\hline Vigo Guixar & $\begin{array}{c}\text { Barcelona } \\
\text { Morrot }\end{array}$ & $20: 30$ & $22: 22$ & LMXJV-- & $\begin{array}{c}\text { Monforte-León- } \\
\text { Miranda. }\end{array}$ \\
\hline Lugo & $\begin{array}{c}\text { Madrid- } \\
\text { Abrońigal }\end{array}$ & $21: 55$ & $11: 30$ & LMXJV-- & Monforte. \\
\hline Gijón-Avilés & $\begin{array}{c}\text { Madrid- } \\
\text { Abrońigal }\end{array}$ & $22: 05$ & $10: 15$ & LMXJV-- & Lugo LI.-León. \\
\hline
\end{tabular}

Fuente: RENFE. Elaboración Propia.

Todos los servicios son cubiertos por trenes TECO que comunica a terminales terrestres.

(*) Admiten carga y descarga de contenedores.

Todas las unidades tienen conexión con cualquier país europeo a través de la red EUROTECO.

Existe la posibilidad de contratar el servicio de TREN CLIENTE en el caso de que las ofertas horarias no se ajusten a las exigencias de la demanda.

Los valores consignados en la tabla $n^{\circ} 4.3$ nos muestran las ofertas de servicio ferroviario cubierto por los Trenes Combinados RENFE para la unidad territorial Centro. La información de la tabla nos indica que la oferta de tráfico con extremo de viaje en Madrid-Abroñigal disfruta de un amplio abanico de conexiones territoriales. A nuestro estudio le interesan básicamente dos conexiones:

a) La articulación ferroviaria Madrid-Abroñigal-A Coruña San Diego.

b) La oferta de tráfico Madrid-Abroñigal-Lugo.

Estas dos ofertas de tráfico presentan una regularidad casi semanal en el caso de la comunicación con A Coruña San Diego y con Lugo. El único día semanal en el cual no se registra oferta de servicio para cada uno de los dos sentidos del tráfico es en domingo. La operatividad ferroviaria del Transporte Combinado RENFE tiene a Monforte-Lugo como el centro intermodal de mercancías para las cargas movilizadas por contenedor. Por último, los datos de la tabla nos muestran un último factor. En efecto, se trata ahora de señalar cuál es la oferta de transporte hacia la fachada mediterránea y hacia Andalucía. Los datos reflejan una óptima dotación de conectividad con Valencia, Barcelona y con Algeciras. 


\begin{tabular}{|c|c|c|c|c|c|}
\hline \multicolumn{6}{|c|}{$\begin{array}{c}\text { Tabla } n^{\circ} \text { 4.3. Oferta de servicio mediante Transporte Combinado RENFE en la unidad } \\
\text { territorial Centro. }\end{array}$} \\
\hline Origen & Destino & $\begin{array}{l}\text { Hora } \\
\text { salida. }\end{array}$ & $\begin{array}{l}\text { Hora } \\
\text { Llegada. }\end{array}$ & $\begin{array}{l}\text { Días } \\
\text { Circulación. }\end{array}$ & Intervenciones. \\
\hline $\begin{array}{l}\text { Madrid- } \\
\text { Abrońigal. }\end{array}$ & A Coruña S.D. & 16:10 & 09:55 & LMXJV-D & Monforte-Lugo. \\
\hline $\begin{array}{l}\text { Madrid- } \\
\text { Abrońigal. }\end{array}$ & Algeciras. ${ }^{1}$ & $17: 45$ & 08:55 & LMXJVS- & Córdoba-S. Roque. \\
\hline $\begin{array}{l}\text { Madrid- } \\
\text { Abron̂igal. }\end{array}$ & Gijón-Avilés. & $00: 40$ & $17: 39$ & LMXJV-- & $\begin{array}{l}\text { Valladolid-León Clasif. } \\
\text {-Viella. }\end{array}$ \\
\hline $\begin{array}{l}\text { Madrid- } \\
\text { Abrońigal. }\end{array}$ & $\begin{array}{l}\text { Barcelona } \\
\text { Morrot. }\end{array}$ & 18:55 & $04: 40$ & LMXJVS- & \\
\hline $\begin{array}{l}\text { Madrid- } \\
\text { Abrońigal. }\end{array}$ & $\begin{array}{l}\text { Bilbao } \\
\text { Parque. }\end{array}$ & 17:10 & 06:05 & LMXJV-D & $\begin{array}{l}\text { Aranda de Duero- } \\
\text { Miranda de Ebro. }\end{array}$ \\
\hline $\begin{array}{l}\text { Madrid- } \\
\text { Abrońigal. }\end{array}$ & Cádiz. ${ }^{1}$ & $18: 20$ & 09:50 & LMXJV-D & $\begin{array}{c}\text { Córdoba-Sevilla la } \\
\text { Negrilla-Pto. Sta. } \\
\text { María. }\end{array}$ \\
\hline $\begin{array}{l}\text { Madrid- } \\
\text { Abrońigal. }\end{array}$ & $\begin{array}{c}\text { Irún (S. } \\
\text { Sebastián). }\end{array}$ & 02:00 & $12: 30$ & LMXJ-S- & \\
\hline $\begin{array}{c}\text { Madrid- } \\
\text { Abrońigal. }\end{array}$ & Lugo. & 16:10 & 09:55 & LMXJV-D & Monforte-Lugo. \\
\hline $\begin{array}{c}\text { Madrid- } \\
\text { Abrońigal. }\end{array}$ & Mérida. & 16:35 & $01: 36$ & L----V-- & Plasencia. \\
\hline $\begin{array}{c}\text { Madrid- } \\
\text { Abrońigal. }\end{array}$ & Murcia & $22: 20$ & $08: 43$ & LMXJ--D & Alicante Benalua. \\
\hline $\begin{array}{c}\text { Madrid- } \\
\text { Abrońigal. }\end{array}$ & Puertollano. & $04: 25$ & $08: 14$ & L-X---- & \\
\hline $\begin{array}{c}\text { Madrid- } \\
\text { Abrońigal. }\end{array}$ & Port. Bou. & $15: 30$ & $06: 50$ & LMXJV-- & $\begin{array}{c}\text { CIM Zaragoza- } \\
\text { Granollers. }\end{array}$ \\
\hline $\begin{array}{c}\text { Madrid- } \\
\text { Abrońigal. }\end{array}$ & $\begin{array}{l}\text { Santander- } \\
\text { Muiedas. }\end{array}$ & 23:30 & 09:48 & L-X-V-- & Torrelavega. \\
\hline $\begin{array}{c}\text { Madrid- } \\
\text { Abrońigal. }\end{array}$ & Santurce. ${ }^{1}$ & 21:00 & 05:55 & -MXJVSD & \\
\hline $\begin{array}{l}\text { Madrid- } \\
\text { Abrońigal. }\end{array}$ & $\begin{array}{l}\text { Sevilla- } \\
\text { Huelva. }\end{array}$ & $21: 44$ & 06:57 & LMXJV-- & $\begin{array}{c}\text { Linares B.- Córdoba } \\
\text { Hig. (Málaga). }\end{array}$ \\
\hline $\begin{array}{l}\text { Madrid- } \\
\text { Abrońigal. }\end{array}$ & $\begin{array}{l}\text { Valencia- } \\
\text { Silla. }\end{array}$ & 23:00 & 05:02 & LMXJV- & \\
\hline $\begin{array}{c}\text { Madrid- } \\
\text { Abrońigal. }\end{array}$ & $\begin{array}{l}\text { Valencia- } \\
\text { Grao. }\end{array}$ & 00:05 & 06:58 & -MXJVS- & \\
\hline
\end{tabular}

Fuente: RENFE. Elaboración Propia.

(1) Oferta de servicio cubierta por la comercialización del TREN PUERTO. Este tipo de ofertas de transporte se destinan a cubrir las terminales portuarias.

Los restantes servicios de la zona Centro son cubiertos por trenes TECO que comunica a terminales terrestres.

(*) Admiten carga y descarga de contenedores.

Todas las unidades tienen conexión con cualquier país europeo a través de la red EUROTECO.

Existe la posibilidad de contratar el servicio de TREN CLIENTE en el caso de que las ofertas horarias no se ajusten a las exigencias de la demanda. 
Los registros computados en la tabla no 4.4 reflejan una información semejante a la comentada para la unidad territorial ferroviaria Centro. En este caso se trata de la oferta regular de servicio cubierta por los trenes Transporte Combinado RENFE para la unidad territorial Cataluña. Los registros de la tabla únicamente señalan a una única conexión territorial entre Cataluña y Galicia. Como se indica, se trata de la relación Barcelona Morrot-Vigo Guixar. La oferta de servicio para cada uno de los dos sentidos del tráfico es casi semanal. El único día en el cual no existe expedición es el sábado. La operatividad de este tráfico está organizada desde Miranda-León y Monforte. Al examinar la oferta de servicio entre las dos estaciones ferroviarias se advierte como los tráficos movilizados experimentan unos importantes retrasos en cubrir los dos extremos de viaje. La duración media de los recorridos estaba fijada por la UNE Transporte Combinado RENFE en una media de 13 horas y 15 minutos. Este valor nos pone en la pista de que determinado tipo de mercancías pueden no decantarse por el modo de transporte ferroviario a la hora de realizar sus flujos.

\begin{tabular}{|c|c|c|c|c|c|}
\hline \multicolumn{6}{|c|}{$\begin{array}{c}\text { Tabla } n^{\circ} \text { 4.4. Oferta de servicio mediante Transporte Combinado RENFE en la unidad } \\
\text { territorial Cataluña. }\end{array}$} \\
\hline Origen & Destino. & $\begin{array}{l}\text { Hora } \\
\text { Salida. }\end{array}$ & $\begin{array}{c}\text { Hora } \\
\text { Llegada. }\end{array}$ & $\begin{array}{l}\text { Días } \\
\text { circulación. }\end{array}$ & Intervenciones. \\
\hline $\begin{array}{l}\text { Barcelona } \\
\text { Morrot. }\end{array}$ & $\begin{array}{l}\text { Madrid- } \\
\text { Abrońigal. }\end{array}$ & 19:15 & 05:10 & LMXJVS- & \\
\hline $\begin{array}{l}\text { Barcelona } \\
\text { Morrot. }\end{array}$ & Bilbao Parque. & $17: 45$ & 07:02 & LMXJV-- & $\begin{array}{l}\text { CIM Zaragoza- } \\
\text { Miranda de Ebro. }\end{array}$ \\
\hline $\begin{array}{l}\text { Barcelona } \\
\text { Morrot. }\end{array}$ & $\begin{array}{l}\text { Valencia- } \\
\text { Grao. }^{1}\end{array}$ & $20: 45$ & $02: 40$ & LMXJV-- & \\
\hline $\begin{array}{l}\text { Barcelona } \\
\text { Morrot. }\end{array}$ & $\begin{array}{l}\text { Algeciras- } \\
\text { S. Roque. }\end{array}$ & $01: 20$ & $13: 42$ & LMXJVSD & $\begin{array}{c}\text { Silla-Córdoba } \\
\text { (Málaga). }\end{array}$ \\
\hline $\begin{array}{l}\text { Barcelona } \\
\text { Morrot. }\end{array}$ & $\begin{array}{c}\text { Sevilla- } \\
\text { Huelva-Cádiz. }\end{array}$ & 05:05 & $00: 25$ & -MXJVSD & $\begin{array}{c}\text { CIM Zaragoza- } \\
\text { Córdoba. }\end{array}$ \\
\hline $\begin{array}{l}\text { Barcelona } \\
\text { Morrot. }\end{array}$ & Santurce. ${ }^{1}$ & 16:35 & $05: 15$ & -M-J-S- & \\
\hline $\begin{array}{c}\text { Barcelona } \\
\text { Morrot. }\end{array}$ & Vigo Guixar. & $20: 15$ & $21: 30$ & LMXJV-D & $\begin{array}{c}\text { Miranda-León } \\
\text { (Avilés)-Monforte. }\end{array}$ \\
\hline $\begin{array}{c}\text { Barcelona } \\
\text { Morrot. }\end{array}$ & $\begin{array}{l}\text { Santander- } \\
\text { Torrelavega. }\end{array}$ & $16: 35$ & $07: 40$ & L-X-V-- & CIM Zaragoza. \\
\hline $\begin{array}{c}\text { Barcelona } \\
\text { Morrot. }\end{array}$ & Valencia-Silla. ${ }^{1}$ & 03:47 & 09:40 & -MXJVSD & \\
\hline
\end{tabular}

Fuente: RENFE. Elaboración Propia.

(1) Oferta de servicio cubierta por la comercialización del TREN PUERTO. Este tipo de ofertas de transporte se destinan a cubrir las terminales portuarias.

(*) Admiten carga y descarga de contenedores. Los restantes servicios de la zona Centro son cubiertos por trenes TECO que comunica a terminales terrestres.

Todas las unidades tienen conexión con cualquier país europeo a través de la red EUROTECO.

Existe la posibilidad de contratar el servicio de TREN CLIENTE en el caso de que las ofertas horarias no se ajusten a las exigencias de la demanda. 


\begin{tabular}{|c|c|c|c|c|c|}
\hline \multicolumn{6}{|c|}{$\begin{array}{c}\text { Tabla } n^{\circ} \text { 4.5. Oferta de servicio mediante Transporte Combinado RENFE en la unidad } \\
\text { territorial Levante. }\end{array}$} \\
\hline Origen & Destino. & $\begin{array}{l}\text { Hora } \\
\text { Salida. }\end{array}$ & $\begin{array}{c}\text { Hora } \\
\text { Llegada. }\end{array}$ & $\begin{array}{c}\text { Días } \\
\text { circulación. }\end{array}$ & Intervenciones. \\
\hline Murcia. & $\begin{array}{l}\text { Madrid- } \\
\text { Abrońigal. }\end{array}$ & $19: 20$ & 05:00 & LMXJV-- & Alicante Benalua. \\
\hline Valencia-Silla & $\begin{array}{l}\text { Madrid- } \\
\text { Abrońigal. }\end{array}$ & 22:05 & $04: 30$ & LMXJV-- & \\
\hline Valencia-Silla & $\begin{array}{l}\text { Barcelona-C. } \\
\text { Antun. }\end{array}$ & $20: 42$ & 02:52 & LMXJVS- & \\
\hline Valencia-Silla & Santurce. & $04: 55$ & $23: 40$ & --XJVSD & $\begin{array}{l}\text { CIM Zaragoza- } \\
\text { Miranda de Ebro. }\end{array}$ \\
\hline Valencia-Grao. & $\begin{array}{c}\text { Madrid- } \\
\text { Abrońigal. }\end{array}$ & $21: 10$ & 03:50 & LMXJV-- & \\
\hline Valencia-Grao. & $\begin{array}{l}\text { Barcelona- } \\
\text { Morrot. }\end{array}$ & 01:10 & 09:20 & -MXJVS- & \\
\hline
\end{tabular}

Fuente: RENFE. Elaboración Propia.

1) Tren PUERTO. Conecta las terminales portuarias.

2) Tren TECO. Conecta terminales terrestres.

3) (*) Admiten carga y descarga de contenedores. Todas las unidades tienen conexión con cualquier país europeo a través de la red EUROTECO. En caso de que la oferta horaria no se ajustase a las necesidades reales de la demanda ésta podía solicitar la comercialización de un TREN CLIENTE.

\section{La matriz ferroviaria de viaje O-D Galicia: Los factores de la caída del transporte ferroviario de mercancías}

La importante caída que ha experimentado el transporte ferroviario de mercancías en España ha originado que el Consejo de Administración de RENFE fomentase una especialización y una mejora operativa de cada unidad comercial. El objetivo era tratar de sanear la cuenta de resultados de las Unidades de Negocio Cargas y adecuarla a las necesidades reales de las economías regionales. Por tal causa, la comercialización del producto Transporte Combinado RENFE trataba de adecuar mejor de la oferta regular de viaje a la sinergia de la generación de flujos de cada territorio regional. La puesta en servicio de este producto dio lugar a que la caída no fuese tan acusada como venían indicando los registros de tráfico movilizado y la recaudación por prestación de servicio. Los factores que podrían invertir esta tendencia y decantarla favorable al ferrocarril, en virtud de sus potencialidades internas y de las exigencias que la política europea del transporte le ha asignado al tren, serían básicamente cuatro:

a) Fomentar la puesta en funcionamiento una planificación destinada a modernizar la infraestructura y el material rodante ferroviario para mejorar $y$ fortalecer sus niveles de calidad al concurrir en los mercados. 
b) La necesidad de definir un modelo de gestión más ajustado a las especificidades del transporte ferroviario y capaz de adaptarse al sistema productivo regional en el cual presta servicio.

c) La importancia de aplicar los avances tecnológicos al sistema de producción ferroviario para incrementar los niveles de calidad en atención al cliente y evitar las rupturas de carga. En este sentido, merece que se indique que en Galicia no se está poniendo en funcionamiento los sistemas inteligentes de gestión del tráfico de mercancías (Electronic Date Interchange). ${ }^{9}$

d) Comercializar una prestación de servicio por tren atractiva desde el plano tarifario respecto de los propios con los que está concurriendo la carretera. Este factor lograría tres efectos paralelos. Por un lado, captar cuota de mercado y fidelizar clientes. En segundo lugar, impulsar la operatividad de un sistema de transporte que se fundamente en la movilidad sostenible. Para ello, se requiere con determinación que la política ferroviaria española camine hacia la especialización y la complementariedad modal. En tercer lugar, se trataría de favorecer la puesta en funcionamiento de un sistema de transporte especializado y capaz de impulsar un importante ahorro de recursos energéticos.

$\mathrm{Al}$ analizar de manera conjunta las informaciones estadísticas de las tablas correspondientes a la matriz ferroviaria de viaje O-D de las estaciones gallegas se pueden alcanzar siete conclusiones:

1) La caída del tonelaje movilizado por el ferrocarril en las provincias gallegas ha sido un factor que nos indica que las medidas correctoras diseñadas por la Dirección Comercial de RENFE no habían alcanzado la eficacia esperada.

2) La matriz de viaje O-D deja a la luz como las provincias gallegas experimentan una destacada pérdida de relaciones territoriales. Este hecho es muy acentuado a escala regional, pero si la matriz mostrase las relaciones provinciales aún lo sería mucho más.

3) Las principales relaciones ferroviarias con extremo de viaje en Galicia comienzan a experimentar importantes cambios. Por una parte, los tradicionales puntos que establecían relaciones con las estaciones gallegas (Castilla y León, Madrid y Cataluña) comienzan a dejar paso a otras relaciones (Va-

9 Para obtener un sistema de transporte ferroviario especializado y competitivo en niveles de calidad es preciso que se ponga en funcionamiento un sistema inteligente de transporte. Esta figura la pueden proporcionar el Electronic Date Interchange (E.D.I), se fundamenta en un sistema de información de intercambio electrónico de datos. Este sistema posibilita el intercambio de información y el conocimiento de la situación de las cargas movilizadas en tiempo real. Nótese a este efecto como el modelo de gestión GOYA y SACICO no habían sido introducidos en la operatividad del transporte de Galicia. 
lencia). No obstante, la magnitud de las mercancías movilizadas no totaliza unos registros mínimamente próximos a los de etapas anteriores.

4) La incidencia de la modernización de la malla viaria española operativa mediante redes de alta capacidad le originó al tren una sobresaliente pérdida de cuota de mercado. El ejemplo más destacado lo constituye la entrada en servicio de la red española de autovías, así como también la malla gallega de vías de alta capacidad: autopistas, autovías y vías rápidas autonómicas.

5) Los principales flujos de mercancías de Galicia muestran como los tráficos intrarregionales son los que totalizan los valores más elevados del tonelaje movilizado.

6) La naturaleza de las principales mercancías movilizadas con extremo de viaje en Galicia no difiere en nada de los tradicionales nichos de mercado: maderas, áridos, material de la construcción, cemento, cereal, granito y piedras, automóviles.

7) No se ha logrado amplificar las oportunidades que el ferrocarril le ocasiona a la oferta de transporte de mercancías a tratar de realizar una óptima interconexión modal carretera-ferrocarril-puerto. Para ello, la planificación debía impulsar la configuración de ejes de de conexión puerto-ciudad por vía ferroviaria. En Galicia el único eje que está funcionando en unos niveles adecuados al volumen de mercancías cargadas/descargadas de una terminal portuaria es el ferrocarril Marín-Pontevedra. Por su parte, la oferta de servicio de Vigo está muy por debajo de los tonelajes embarcados/desembarcados. Esto mismo sucede en A Coruña. Por su parte Ferrol y Vilagarcía están acusando una situación mucho más adversa por no aprovechar las oportunidades del tren al movimiento de las mercancías.

Una vez que se ha efectuado una síntesis de las principales claves explicativas que nos indican cuáles son las razones de la caída continua de los registros del tonelaje de mercancías movilizados por el ferrocarril, cabe detenerse en el análisis detallado de la matriz de viaje O-D a escala provincial de Galicia respecto de las CC.AA españolas. Los valores contemplados en la tabla $n^{\circ} 5.1$ nos muestran el perfil que refleja la matriz de viaje ferroviaria O-D de las provincias de A Coruña y Lugo para el año 2004. En la tabla n ${ }^{\circ} 5.2$ se han computado los valores del transporte ferroviario de mercancías entrado o salido de las provincias de Ourense y Pontevedra para 2004. Al realizar las matrices ferroviarias de viaje correspondientes al transporte de mercancías de las provincias gallegas respecto de las Comunidades Autónomas españolas hemos podido extraer varias conclusiones significativas:

1) Importante caída de la cuota de mercado del transporte ferroviario entrado o salido de las provincias de Galicia. 
2) Fuerte concentración de tráficos ferroviarios. Las relaciones ferroviarias de las provincias gallegas se encuentran muy reducidas en número a unas pocas Comunidades Autónomas. Aún más, si los datos fuesen desagregados por provincias apreciaríamos como las relaciones interprovinciales reflejarían tráficos inexistentes entre muchas de las provincias españolas y las gallegas. Nótese a este efecto que existen numerosas Comunidades Autónomas que presentan nulos tráficos de mercancías.

3) Se advierte como el ferrocarril registra tráficos con algunas CC.AA. que se encuentran muy alejadas geográficamente de Galicia: Valencia, Murcia y Andalucía.

4) La notable caída del tonelaje entrado y salido de las provincias gallegas nos aclara la incidencia que le originó al ferrocarril el proceso de modernización de la red de carreteras.

a) Los valores totales de mercancías entradas y salidas de A Coruña también han experimentado una ostensible caída en el tonelaje respecto de períodos precedentes. Las principales relaciones ferroviarias en tráfico de mercancías de A Coruña son las comunicaciones de esta provincia respecto de Aragón, Castilla-León, Madrid y Comunidad Valenciana.

5) Los registros proporcionados por la Dirección de Informática aparecen agregados en términos de tonelaje total. No se puede conocer con detalle la intensidad de los tráficos ferroviarios según la componente direccional del transporte. De igual manera, tampoco se puede conocer el total de vagones completos movilizados por cada sentido del tráfico.

Al comenzar con el estudio de la matriz ferroviaria correspondiente al transporte de mercancías entradas o salidas de A Coruña, varias son las características que se pueden individualizar en los registros contenidos en la tabla $\mathrm{n}^{\circ}$ 5.1.

a) Los valores de mercancías movilizadas de A Coruña respecto de su propia Comunidad Autónoma no han sido contabilizados. Este es un tráfico intrarregional que en el nuevo modelo de registro de tráfico comercial elaborado por el Departamento de Informática se reservaba para la Dirección Comercial de Cargas Galicia. Así, estos valores se obtenían del estudio de las series facilitadas por la U.N.E. Regionales.

b) Al examinar la magnitud de los flujos advertimos como para el capítulo de tráfico ferroviario total se aprecian numerosas relaciones que movilizan cero toneladas para los dos sentidos del tráfico.

c) Los tráficos totales de mercancías movilizados por el tren en A Coruña nos indican que esta es la provincia que moviliza los mayores niveles de mercancías a escala interregional. 
Para el caso de Lugo, los valores reflejados en la tabla nos señalan las características siguientes:

e) La caída de los registros del transporte ferroviario de mercancías ha sido muy destacada.

f) Las principales relaciones ferroviarias que ostentan Lugo en lo concerniente a tráfico de mercancías son tres: Lugo-Madrid, Lugo-Comunidad Valenciana y Lugo-Andalucía. Ahora bien, si examinamos los valores totales del tonelaje apreciamos como los registros han experimentado una notable caída.

g) La homogeneidad territorial alcanzada por el tren en Lugo es muy pequeña. Únicamente existen cinco relaciones ferroviarias a escala de las Comunidades Autónomas.

h) Se aprecia como existen relaciones de una importancia relativa entre Lugo y las Comunidades Autónomas que se encuentran geográficamente más alejadas: Comunidad Valenciana y Andalucía. El caso de Madrid es diferente, ya que se trata de uno de los principales centros económicos españoles.

i) Los valores cuantificados no muestran los tráficos intrarregionales.

\begin{tabular}{|c|c|c|c|c|c|c|c|}
\hline Año. & A Coruña & CC.AA. & Tn Total & Año. & Lugo. & CC.AA. & Tn Total. \\
\hline 2004 & A Coruña & Galicia. & -- & 2000 & Lugo & Galicia. & -- \\
\hline 2004 & A Coruña & Navarra. & 0 & 2000 & Lugo & Navarra. & 0 \\
\hline 2004 & A Coruña & País Vasco. & $19.811,7$ & 2000 & Lugo. & País Vasco. & 4,3 \\
\hline 2004 & A Coruña & La Rioja. & 0 & 2000 & Lugo & La Rioja. & 0 \\
\hline 2004 & A Coruña & Espańa. & $394.653,8$ & 2000 & Lugo & España. & $100.112,7$ \\
\hline 2004 & A Coruña & Andalucía & $36.145,3$ & 2000 & Lugo & Andalucía & $12.898,5$ \\
\hline 2004 & A Coruña & Aragón. & $159.938,0$ & 2000 & Lugo. & Aragón. & $4.238,5$ \\
\hline 2004 & A Coruña & Asturias. & 49,5 & 2000 & Lugo & Asturias. & 0 \\
\hline 2004 & A Coruña & Cantabria. & 15,8 & 2000 & Lugo & Cantabria. & 0 \\
\hline 2004 & A Coruña & Castilla-La Mancha. & $9.911,8$ & 2000 & Lugo. & Castilla-La Mancha. & 0 \\
\hline 2004 & A Coruña & Castilla-León. & 112.058 & 2000 & Lugo & Castilla-León. & 117,6 \\
\hline 2004 & A Coruña & Cataluña. & $8.163,7$ & 2000 & Lugo & Cataluña. & $1.790,0$ \\
\hline 2004 & A Coruña & Comun.Valenciana. & $31.356,7$ & 2000 & Lugo. & Comun. Valenciana. & $20.151,0$ \\
\hline 2004 & A Coruña & Extremadura. & 0 & 2000 & Lugo & Extremadura. & 0 \\
\hline 2004 & A Coruña & Madrid. & $9.472,7$ & 2000 & Lugo. & Madrid. & $52.779,6$ \\
\hline 2004 & A Coruña & Murcia. & $7.730,6$ & 2000 & Lugo & Murcia. & $8.133,2$ \\
\hline
\end{tabular}

Fuente: RENFE. Elaboración propia.

(*) El ejercicio económico de 1983 es el primer ańo en el cual existen datos fiables sobre la demanda regional de movilidad por ferrocarril. 
En la tabla $\mathrm{n}^{\circ} 5.2$ se ha cuantificado la información correspondiente al segmento de mercancías para el año 2004 de Ourense y Pontevedra. Así, las principales características que externaliza la matriz de viaje de Ourense son:

a) Se ha producido una fortísima pérdida de cuota de mercado en el transporte de mercancías por ferrocarril. El modo ferroviario se ha situado en una posición no rentable para la explotación de servicio de mercancías a escala interregional.

b) Los tráficos habidos en la provincia, aparte de ser muy bajos, únicamente son tres relaciones: Ourense-Andalucía, Ourense-Aragón y Ourense-Castilla y León.

c) El nivel de las relaciones ferroviarias de Ourense para los flujos interregionales es casi nulo.

\begin{tabular}{|c|c|c|c|c|c|c|c|}
\hline Año. & Ourense & CC.AA. & Tn Total & Año. & Pontevedra. & CC.AA. & Tn Total. \\
\hline 2004 & Ourense & Andalucía & 19 & 2000 & Pontevedra & Andalucía & $3.976,2$ \\
\hline 2004 & Ourense & Aragón. & $1.247,0$ & 2000 & Pontevedra & Aragón. & $87.617,7$ \\
\hline 2004 & Ourense & Asturias. & 0 & 2000 & Pontevedra & Asturias. & 619,8 \\
\hline 2004 & Ourense & Cantabria. & 0 & 2000 & Pontevedra & Cantabria. & $5.678,9$ \\
\hline 2004 & Ourense & $\begin{array}{c}\text { Castilla-La } \\
\text { Mancha. }\end{array}$ & 0 & 2000 & Pontevedra & $\begin{array}{c}\text { Castilla-La } \\
\text { Mancha. }\end{array}$ & 798,5 \\
\hline 2004 & Ourense & Castilla-León. & 798,5 & 2000 & Pontevedra & Castilla-León. & $17.945,1$ \\
\hline 2004 & Ourense & Cataluña. & & 2000 & Pontevedra & Cataluña. & $25.303,2$ \\
\hline 2004 & Ourense & $\begin{array}{l}\text { Comunidad } \\
\text { Valenciana. }\end{array}$ & 0 & 2000 & Pontevedra & $\begin{array}{l}\text { Comunidad } \\
\text { Valenciana. }\end{array}$ & $18.055,1$ \\
\hline 2004 & Ourense & Extremadura. & 0 & 2000 & Pontevedra & Extremadura. & 38,1 \\
\hline 2004 & Ourense & Galicia. & -- & 2000 & Pontevedra & Galicia. & -- \\
\hline 2004 & Ourense & Madrid. & 0 & 2000 & Pontevedra & Madrid. & $73.615,7$ \\
\hline 2004 & Ourense & Murcia. & 0 & 2000 & Pontevedra & Murcia. & 0 \\
\hline 2004 & Ourense & Navarra. & 0 & 2000 & Pontevedra & Navarra. & 0 \\
\hline 2004 & Ourense & País Vasco. & 0 & 2000 & Pontevedra & País Vasco. & $25.837,9$ \\
\hline 2004 & Ourense & La Rioja. & 0 & 2000 & Pontevedra & La Rioja. & 0 \\
\hline 2004 & Ourense & España. & $2.054,5$ & 2000 & Pontevedra & España. & $259.486,2$ \\
\hline
\end{tabular}

Fuente: RENFE. Elaboración propia.

(*) El ejercicio económico de 1983 es el primer ańo en el cual existen datos fiables sobre la demanda regional de movilidad por ferrocarril. 
Por lo que hace referencia a los valores del transporte de mercancías movilizado entre Pontevedra y las Comunidades Autónomas españolas, las características más destacadas para el año 2004 son las siguientes:

a) Se ha producido una ligera recuperación del transporte ferroviario total respecto de los valores de 1998. Ahora bien, la recuperación resulta mínima si comparamos la cuota de mercado de este ejercicio respecto del totalizado por etapas precedentes.

b) Las principales relaciones ferroviarias correspondientes al tráfico de mercancías llegado o salido de Pontevedra se encuentran muy concentrado en unas pocas relaciones: Pontevedra-Aragón, Pontevedra-Madrid, PontevedraCataluña y Pontevedra-Valencia. Las restantes alcanzan unos flujos muy modestos en su tonelaje total.

c) Se aprecia como el ferrocarril se está especializando en la realización de transportes a distancias muy alejadas: Madrid, Aragón, Cataluña y Valencia. Por su parte, la caída del tráfico en aquellos nichos de mercado tradicionales es claro: retroceso en las relaciones con Castilla-León.

\section{La matriz de viaje O-D correspondiente al transporte ferroviario de mercancías según la naturaleza del tráfico movilizado para las estaciones de Galicia}

El estudio de la matriz de viaje O-D correspondiente al transporte ferroviario de mercancías se completa con el análisis de la matriz O-D correspondiente a cada una de las principales estaciones ferroviarias gallegas. La Dirección de Informática de RENFE ha elaborado registros desagregados a escala de las estaciones según el montante total de los tráficos entrados y salidos. Por otra parte, se puede apreciar la intensidad de los flujos según el total del tonelaje movilizado según el vector direccional del tráfico: salida y entrada en las terminales ferroviarias.

En los valores de la tabla de mercancías movilizadas para 2004 se puede conocer con precisión la naturaleza de las mercancías entradas o salidas de las estaciones. Este avance en la desagregación de la información del tráfico ferroviario nos muestra cuáles son los principales segmentos del mercado en los cuales se ha especializado cada estación. Por otro lado, se puede examinar el total de las mercancías movilizadas por estación. Por último, y ello no en importancia, se puede examinar el nivel de diversificación y especialización que alcanza cada estación ferroviaria en Galicia. 


\begin{tabular}{|c|c|c|c|c|}
\hline Año. & Estación. & Tn Origen. & Tn. Destino. & Naturaleza de la mercancía. \\
\hline 2004 & Meirama & 3.422 & 600 & Maderas. \\
\hline 2004 & Meirama & 0 & $137.110,2$ & UTI Terrestre cargado. \\
\hline 2004 & Monforte de Lemos & $26.211,3$ & 0 & UTI Terrestre vacío. \\
\hline 2004 & Monforte de Lemos & 0 & 800 & Cereales. \\
\hline 2004 & Neda & 722 & 0 & Maderas \\
\hline 2004 & O Carballiño & 0 & 7.101,6 & Cemento. \\
\hline 2004 & O Carballiño & 1.211 & 0 & Maderas. \\
\hline 2004 & Ordes-Pontraga & 0 & $8.100,6$ & Cemento. \\
\hline 2004 & Ordes-Pontraga & 40,8 & 0 & Envases vacíos. \\
\hline 2004 & Ordes-Pontraga & $1.333,0$ & 0 & Maderas. \\
\hline 2004 & Ordes-Pontraga & 0 & 533,2 & Productos siderúrgicos (No CECA). \\
\hline 2004 & Ourense-Empalme & 68,9 & 0 & Automóviles nacionales. \\
\hline 2004 & Ourense-Empalme & 0 & $98.755,4$ & Cemento. \\
\hline 2004 & Ourense-Empalme & 0 & 966,5 & Cereales. \\
\hline 2004 & Ourense-Empalme & 279,2 & 0 & Envases vacíos. \\
\hline 2004 & Ourense-Empalme & 0 & $61.080,0$ & Piedras y tierras. \\
\hline 2004 & Ourense-Empalme & 0 & $4.119,7$ & Productos siderúrgicos (No CECA) \\
\hline 2004 & Ourense-Empalme & 0 & 23,4 & Textil, aparatos, máquinas \\
\hline 2004 & Ourense-Empalme & 26 & 366 & Transportes especiales. \\
\hline 2004 & Ourense-Empalme & 0 & 55,4 & Madera internacional. \\
\hline 2004 & Ourense-Empalme & 0 & 597,6 & Productos siderúrgicos (No CECA) \\
\hline 2004 & Oural & 0 & 677,0 & Envases vacíos. \\
\hline 2004 & Padrón & 2.887 & 0 & Maderas. \\
\hline 2004 & Pontedeume & 6.116 & 0 & Maderas. \\
\hline 2004 & Pontevedra & 0 & $15.228,4$ & Cemento. \\
\hline 2004 & Pontevedra & $87.007,6$ & $6.115,4$ & Cereales. \\
\hline 2004 & Pontevedra & 7 & 0 & Envases vacíos. \\
\hline 2004 & Pontevedra & $1.950,6$ & 1.789 & Maderas. \\
\hline 2004 & Pontevedra & 78 & 0 & Materiales textiles. \\
\hline 2004 & Pontevedra & 1.050 & 977 & Transportes militares. \\
\hline 2004 & Subtotal. & $132.410,4$ & $344.996,4$ & \\
\hline
\end{tabular}

Fuente: RENFE. Dirección de Informática. Elaboración propia. 
Tabla $n^{\circ}$ 6.1. (Continuación). Matriz de viaje O-D del transporte ferroviario de mercancías correspondiente a las estaciones gallegas según la naturaleza de las cargas movilizadas. 2004

\begin{tabular}{|l|c|c|c|c|}
\hline Año. & Estación. & Tn Origen. & Tn. Destino. & Naturaleza de la mercancía. \\
\hline 2004 & Porriño & 0 & 688 & Automóviles nacionales. \\
\hline 2004 & Porriño & 0 & 26 & Textil, aparatos máquinas. \\
\hline 2004 & Portas & 0 & $65.157,9$ & Cemento. \\
\hline 2004 & Pontecesures & $5.527,8$ & 0 & Maderas. \\
\hline
\end{tabular}

\begin{tabular}{|l|c|c|c|c|}
\hline 2004 & Pontecesures & $5.527,8$ & 0 & Maderas. \\
\hline 2004 & Rábade & 0 & $8.776,1$ & Cereal. \\
\hline 2004 & Rábade & 0 & 452 & Cereal internacional. \\
\hline
\end{tabular}

\begin{tabular}{|l|c|c|c|c|}
\hline 2004 & Rábade & 0 & $2.511,6$ & Maderas. \\
\hline 2004 & Rábade & 0 & 311 & Madera internacional. \\
\hline 2004 & Redondela & 0 & $5.050,3$ & Cereal. \\
\hline 2004 & Redondela & $2.879,3$ & 27.001 & Material de construcción. \\
\hline
\end{tabular}

\begin{tabular}{|c|c|c|c|c|}
\hline 2004 & Redondela & $2.8 / 9,3$ & 27.001 & Material de construccion. \\
\hline 2004 & Redondela & 2 & 83,4 & Transportes excepcionales. \\
\hline 2004 & Ribadavia & 0 & $2.566,8$ & Cemento. \\
\hline 2004 & Santiago de Compostela & 208,6 & 746 & Automóviles nacionales. \\
\hline
\end{tabular}

\begin{tabular}{|c|c|c|c|c|}
\hline 2004 & Santiago de Compostela & 208,6 & 746 & tomóviles nacionales. \\
\hline 2004 & Santiago de Compostela & 0 & 999 & Cereal. \\
\hline 2004 & Santiago de Compostela & 178,9 & 19,5 & Envases vacíos. \\
\hline 2004 & Santiago de Compostela & $55.221,5$ & 932 & Maderas. \\
\hline
\end{tabular}

\begin{tabular}{|c|c|c|c|c|}
\hline 2004 & Santiago de Compostela & $55.221,5$ & 932 & Maderas. \\
\hline 2004 & Santiago de Compostela & $42.221,1$ & $17.744,4$ & UTI Terrestre cargado. \\
\hline 2004 & Santiago de Compostela & 644,7 & $4.002,4$ & UTI Terrestre vacío. \\
\hline 2004 & Susana & 0 & $80.561,3$ & Cemento. \\
\hline
\end{tabular}

\begin{tabular}{|l|c|c|c|c|}
\hline 2004 & Susana & & $80.561,3$ & Cemento. \\
\hline 2004 & Susana & 1.800 & 0 & Maderas. \\
\hline 2004 & Taboadela & 0 & 4.333 & Cemento. \\
\hline 2004 & Taboadela & 206,8 & $261.002,3$ & Cereal. \\
\hline
\end{tabular}

\begin{tabular}{|c|c|c|c|c|}
\hline 2004 & Taboadela & 206,8 & $261.002,3$ & Cereal. \\
\hline 2004 & Taboadela & 0 & $42.331,6$ & Maderas. \\
\hline 2004 & Taboadela & 0 & 322 & Textil, aparatos, máquinas. \\
\hline
\end{tabular}

\begin{tabular}{|c|c|c|c|c|}
\hline 2004 & Taboadela & 0 & 322 & Textil, aparatos, máquinas. \\
\hline 2004 & Taboadela & 112,1 & 1 & Transportes especiales \\
\hline 2004 & O Barco de Valdeorras & 0 & 454 & Textil, aparatos, máquinas. \\
\hline 2004 & O Barco de Valdeorras & 86 & 0 & Transportes especiales. \\
\hline 2004 & Betanzos-Ciudad & 0 & $5.223,6$ & Cemento. \\
\hline 2004 & Betanzos-Ciudad & 4.118 & 0 & Maderas. \\
\hline 2004 & Betanzos-Infesta & 5.229 & 4.236 & Maderas. \\
\hline 2004 & Betanzos-Infesta & 407,7 & 0 & Madera internacional. \\
\hline 2004 & Campomarzo & 52.380 & 0 & Piedra y tierra. \\
\hline 2004 & Chapela & 0 & $5.730,3$ & Cemento. \\
\hline 2004 & Subtotal. & $164.553,5$ & $475.495,5$ & \\
\hline
\end{tabular}




\begin{tabular}{|c|c|c|c|c|}
\hline Año. & Estación. & Tn Origen. & Tn. Destino. & Naturaleza de la mercancía. \\
\hline 2004 & Curtis & 0 & $4.716,4$ & Cemento. \\
\hline 2004 & Curtis & 0 & 90 & Cemento. \\
\hline 2004 & Curtis & 1.653 & $9.118,2$ & Maderas. \\
\hline 2004 & O Burgo & $17.991,9$ & 0 & Maderas. \\
\hline 2004 & O Burgo & 1.560 & 0 & Papel. \\
\hline 2004 & Esclavitud & 0 & $3.100,5$ & Productos siderúrgicos (CECA) \\
\hline 2004 & Esclavitud & 5.087 & 0 & Madera. \\
\hline 2004 & Ferrol & 36.257 & 0 & Maderas. \\
\hline 2004 & Ferrol & 799,3 & 0 & Papel. \\
\hline 2004 & Ferrol & $48.524,9$ & 0 & Productos siderúrgicos (CECA). \\
\hline 2004 & Ferrol & 0 & 541 & Productos siderúrgicos (No CECA). \\
\hline 2004 & Guillarei & 1.009 & 0 & Madera. \\
\hline 2004 & A Coruña-San Diego-Contenedor & 3.398 & 264,4 & UTI Cargado Internacional. \\
\hline 2004 & A Coruña-San Diego-Contenedor & $3.877,7$ & $1.785,6$ & UTI Marítimo Cargado. \\
\hline 2004 & A Coruña-San Diego-Contenedor & 703,3 & 984,8 & UTI Marítimo vacío. \\
\hline 2004 & A Coruña-San Diego-Contenedor & $37.218,5$ & $17.552,8$ & UTI Terrestre Cargado. \\
\hline 2004 & A Coruña-San Diego-Contenedor & $2.090,2$ & $3.933,7$ & UTI Terrestre vacío. \\
\hline 2004 & A Coruña-San Diego-Contenedor & $28.450,7$ & 6,9 & UTI Vacío Internacional. \\
\hline 2004 & A Coruña-Puerto. & 0 & 292,5 & Automóviles nacionales. \\
\hline 2004 & A Coruña-San Diego-E. Centro & 0 & 698,8 & Automóviles nacionales. \\
\hline 2004 & A Coruña-San Diego. & 0 & $145.073,3$ & Cemento. \\
\hline 2004 & A Coruña-San Diego. & 0 & 3.989 & Cereal internacional \\
\hline 2004 & A Coruña-San Diego. & 268 & 0 & Comestibles y géneros frescos. \\
\hline 2004 & A Coruña-San Diego. & 234,3 & 0 & Envases vacíos. \\
\hline 2004 & A Coruña-San Diego. & 2.981 & 0 & Maderas. \\
\hline 2004 & A Coruña-San Diego. & 0 & 586,1 & Productos siderúrgicos (CECA) \\
\hline 2004 & A Coruña-San Diego. & 0 & $1.344,9$ & Productos siderúrgicos (No CECA) \\
\hline 2004 & A Coruña-San Diego. & 0 & 102,8 & Productos siderúrgicos (CECA) \\
\hline 2004 & A Coruña-San Diego. & 182 & $3.033,9$ & Textil, aparatos, máquinas. \\
\hline 2004 & A Coruña-San Diego. & 0 & 12,7 & Textil, aparatos, máquinas. \\
\hline 2004 & A Coruña-San Diego. & 3 & 0 & Transportes especiales. \\
\hline 2004 & A Coruña-San Diego. & 0 & 66,5 & Cereales \\
\hline 2004 & Subtotal. & $192.288,8$ & $197.294,8$ & \\
\hline
\end{tabular}


Tabla $n^{\circ}$ 6.1. (Continuación). Matriz de viaje 0-D del transporte ferroviario de mercancías correspondiente a las estaciones gallegas según la naturaleza de las cargas movilizadas. 2004

\begin{tabular}{|c|c|c|c|c|}
\hline Año. & Estación. & Tn Origen. & Tn. Destino. & Naturaleza de la mercancía. \\
\hline 2004 & A Rúa & 0 & 48,5 & Cereal. \\
\hline 2004 & A Rúa & 14.137 & 0 & Material de construcción. \\
\hline 2004 & Laxosa & 0 & 1.694 & Madera. \\
\hline 2004 & Lalín & 17,5 & 0 & Envases vacíos. \\
\hline 2004 & Lalín & $28.846,4$ & 0 & UTI Terrestre Cargado. \\
\hline 2004 & Lalín & 78,7 & $2.843,9$ & UTI Terrestre Vacío. \\
\hline 2004 & As Gándaras & $12.621,4$ & 0 & Automóviles internacionales. \\
\hline 2004 & As Gándaras & $49.115,9$ & $10.425,4$ & Automóviles nacionales. \\
\hline 2004 & As Gándaras & 0 & $71.888,5$ & Cemento. \\
\hline 2004 & As Gándaras & 0 & $14.111,5$ & Cereal. \\
\hline 2004 & As Gándaras & 651,5 & 13 & Envases Vacíos. \\
\hline 2004 & As Gándaras & 0 & 190 & Madera. \\
\hline 2004 & As Gándaras & 987,6 & 14.110 & Material de Construcción. \\
\hline 2004 & As Gándaras & 0 & $14.778,9$ & Cereal. \\
\hline 2004 & Lugo & $1.003,7$ & 0 & Comestibles y generos fresco. \\
\hline 2004 & Lugo & 221,5 & 0 & Productos alimenticios \\
\hline 2004 & Lugo & 11 & 0 & UTI Terrestre cargado. \\
\hline 2004 & Tui-Frontera-Portugal & 10.815 & 0 & Maderas. \\
\hline 2004 & Tui-Frontera-Portugal & 4.014 & 388,7 & Madera internacional. \\
\hline 2004 & Tui-Frontera-Portugal & 0 & $7.028,1$ & Material de construcción. \\
\hline 2004 & Tui-Frontera-Portugal & 0 & $3.056,5$ & Productos siderúrgicos (CECA) \\
\hline 2004 & Tui-Frontera-Portugal & 30 & & Textil, aparatos, máquinas \\
\hline 2004 & Tui-Frontera-Portugal & $4.121,8$ & $3.341,1$ & UTI Cargado Internacional. \\
\hline 2004 & Tui-Frontera-Portugal & 323,6 & 316,2 & UTI Vacío Internacional. \\
\hline 2004 & Vigo-Puerto & $1.998,6$ & 0 & Abonos. \\
\hline 2004 & Vigo-Puerto & $8.776,2$ & 25.324 & Material de construcción. \\
\hline 2004 & Vigo-Puerto & $3.128,1$ & 0 & Material de Construcción. \\
\hline 2004 & Vigo-Guixar & 0 & 6 & Automóviles nacionales. \\
\hline 2004 & Vigo-Guixar & 193,2 & $28.140,6$ & Productos siderúrgicos (CECA) \\
\hline 2004 & Vigo-Guixar & 0 & 36,8 & $\begin{array}{c}\text { Productos siderúrgicos internacio- } \\
\text { nal (CECA). }\end{array}$ \\
\hline 2004 & Vigo-Guixar & 0 & 32,8 & Textil, aparatos, máquinas. \\
\hline 2004 & Vigo-Guixar & 0 & 29,3 & $\begin{array}{c}\text { Transportes excepcionales inter- } \\
\text { nacional. } \\
\end{array}$ \\
\hline 2004 & Subtotal & $141.092,7$ & $57.226,8$ & \\
\hline
\end{tabular}




\begin{tabular}{|c|c|c|c|c|}
\hline Año. & Estación. & Tn Origen. & Tn. Destino. & Naturaleza de la mercancía. \\
\hline 2004 & Vigo-Guixar-Contenedor & 23 & 0 & Productos químicos internacional. \\
\hline 2004 & Vigo-Guixar-Contenedor & $9.437,8$ & $8.611,5$ & UTI cargado Internacional. \\
\hline 2004 & Vigo-Guixar-Contenedor & $7.916,4$ & $9.294,0$ & UTI Marítimo Cargado. \\
\hline 2004 & Vigo-Guixar-Contenedor & $2.037,1$ & $5.468,2$ & UTI Marítimo vacío. \\
\hline 2004 & Vigo-Guixar-Contenedor & $154.221,1$ & $39.112,4$ & UTI Terrestre Cargado. \\
\hline 2004 & Vigo-Guixar-Contenedor & $4.315,8$ & $37.665,0$ & UTI Terrestre vacío. \\
\hline 2004 & Vigo-Guixar-Contenedor & 988,7 & 680,2 & UTI Vacío Internacional. \\
\hline 2004 & Vilagarcía de Arousa & 0 & $42.644,2$ & Cemento. \\
\hline 2004 & Vilagarcía de Arousa & 0 & $1.209,3$ & Cereal \\
\hline 2004 & Vilagarcía de Arousa & 711,6 & 0 & Envases vacíos \\
\hline 2004 & Vilagarcía de Arousa & $9.112,2$ & 0 & Papel \\
\hline 2004 & Vilagarcía de Arousa & 4 & 0 & Transportes excepcionales \\
\hline 2004 & Subtotal. & $188.767,7$ & $144.684,8$ & \\
\hline 2004 & $\begin{array}{l}\text { Total mercancías movilizadas } \\
\text { por las estaciones de Galicia. }\end{array}$ & & & \\
\hline
\end{tabular}

Fuente: RENFE. Dirección de Informática. Elaboración propia.

La tabla $n^{\circ} 6.2$ recoge en su interior los valores de las mercancías ferroviarias totales movilizadas por cada una de las provincias de Galicia. Las cifras reflejadas nos exponen el volumen de negocio totalizado según los transportes totales: tráficos interregionales, internacionales e intrarregionales.

$\mathrm{Al}$ examinar con detenimiento la participación del tonelaje total de la matriz podemos sacar tres conclusiones:

1) El comportamiento del tonelaje total movilizado entre 1998 y 2000 para Galicia y sus provincias.

2) Los valores de las toneladas entradas o salidas de cada provincia: intensidad del tonelaje de las mercancías de llegada o de salida del territorio provincial. Estos valores pueden indicar dos tipos de situaciones. En primer lugar, un equilibrio entre las entradas y las salidas de las mercancías en cada provincia. En segundo lugar, la situación de una asimetría entre los tonelajes de llegada respecto de los de salidas. En el caso de que resulten mayores las salidas de tonelajes puede decirse que la provincia presenta un elevado nivel de generación de mercancías cuyo tonelaje se destina a la exportación. En la situación de que los valores de las mercancías de llegada resulten mucho más elevados que los de salida la situación es inversa. La fuerte demanda de productos que 
presenta una provincia (ejemplo destacado es Ourense) explica los tonelajes de llegada para nutrir a su sistema productivo.

3) Las cifras correspondientes al total de mercancías entradas y salidas de las provincias gallegas nos muestran de manera agregada los valores totales movilizados a escala interprovincial. Por tanto, no se han reflejado los totales de las mercancías movilizadas a nivel intraprovincial para cada una de las provincias de Galicia. La importancia de este indicador es clave para conocer el comportamiento de las interacciones territorial de la provincia en el apartado del tráfico ferroviario. Este tipo de registros pueden ser estudiados de una manera parcial en el análisis de las tablas construidas para los tráficos de cada una de las estaciones de Galicia. Allí se podían conocer el total de los flujos de entrada y salida de cada terminal ferroviaria. No obstante, y como se avanzó, no se aportaba información alguna a propósito de los extremos de viaje $\mathrm{O}-\mathrm{D}$ de las estaciones.

Una vez que se han expuesto los principales factores que caracterizan a la matriz O-D provincial de transporte indicaremos las características más importantes de la tabla:

a) Las provincias que totalizan los valores más elevados para la serie 1998-2004 son A Coruña y Pontevedra.

b) Al examinar la componente direccional de los flujos ferroviarios advertimos como los tráficos de destino son más elevados que los de llegada para el total de Galicia. A escala de cada una de las provincias esta tendencia se confirma aunque existen matices que deben ser destacados. La componente direccional de A Coruña está caracterizado por un ligero mayor peso de los tonelajes de llegada que de salida. Si bien, al valorar la magnitud de cada ejercicio apreciamos como casi existe un equilibrio entre ambos valores en 1998. En los dos ejercicios siguientes el tonelaje de las llegadas es claramente mayor a las salidas. Por lo que concierne a Lugo, la tendencia es simétrica a A Coruña. No obstante, cabe resaltar que los valores totales de las mercancías movilizadas por el tren son mucho más modestos. Los tráficos de Ourense son totalmente asimétricos para los años registrados. El peso de los tráficos ferroviarios de salida es prácticamente marginal. Por su parte, los valores correspondientes a las llegadas son muy importantes en su tonelaje. Finalmente, Pontevedra refleja una situación intermedia a las anteriores provincias. De partida, el tonelaje es de los más elevados de Galicia. Ahora bien, al examinar la componente direccional de los vectores apreciamos como los flujos de llegada es más importante en toneladas movilizadas que el flujo de salida. 


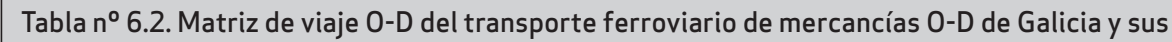
provincias. 1998-2000.

\begin{tabular}{|c|c|c|c|c|}
\hline Año & Provincia. & Tn Origen. & Tn Destino. & Tn Totales. \\
\hline 1998 & A Coruña. & $380.400,8$ & $387.170,9$ & $767.571,7$ \\
\hline 1998 & Lugo & $67.720,4$ & $69.702,9$ & 137.423 \\
\hline 1998 & Ourense. & $2.510,1$ & $425.485,7$ & $427.995,8$ \\
\hline 1998 & Pontevedra. & $327.148,3$ & $448.770,2$ & $757.291,2$ \\
\hline 1998 & Galicia. & $777.779,6$ & $1.331 .129,7$ & $2.090 .281,7$ \\
\hline 2000 & A Coruńa & $319.781,9$ & $437.509,3$ & $757.291,2$ \\
\hline 2000 & Lugo & $99.788,7$ & $172.918,3$ & 272.707 \\
\hline 2000 & Ourense. & $2.051,1$ & $410.345,5$ & $412.396,6$ \\
\hline 2000 & Pontevedra. & $350.424,8$ & $489.341,1$ & $839.766,0$ \\
\hline 2000 & Galicia & $772.046,5$ & $1.510 .114,2$ & $2.282 .160,8$ \\
\hline 2004 & A Coruña. & $310.029,4$ & $378.064,7$ & $688.094,1$ \\
\hline 2004 & Lugo. & $64.346,4$ & $99.538,8$ & $163.885,2$ \\
\hline 2004 & Ourense. & $2.463,9$ & $431.598,7$ & $434.062,6$ \\
\hline 2004 & Pontevedra. & $337.691,7$ & $466.618,3$ & $804.310,0$ \\
\hline 2004 & Galicia. & $714.531,4$ & $1.375 .820,5$ & $2.090 .351,9$ \\
\hline
\end{tabular}

Fuente: RENFE. UNE Cargas. UNE Regionales. Elaboración propia.

\section{Conclusiones}

La oferta de transporte ferroviario de Galicia debe acometer con urgencia un amplio conjunto de mejoras estructurales. El objetivo final es especializar convenientemente la oferta ferroviaria a sus respectivos segmentos del mercado. En la actualidad la carretera ostenta una posición macrocefálica en cuanto a participación de cota de mercado de transporte. Los registros del ferrocarril están cayendo de un modo alarmante. Este hecho nos deja al descubierto que es menester diseñar un Plan de Empresa acorde a las complejidades del transporte de Galicia. Para ello, una de las actuaciones clave será constituir un puerto seco para que el ferrocarril pueda comercializar una oferta logística del transporte donde se pretenda beneficiar al cliente potencial en base a la puesta en marcha de una política tarifaria competitiva y que pretenda la fidelización del cliente.

$\mathrm{Si}$ se examinan los valores de las matrices $\mathrm{O}-\mathrm{D}$ del transporte ferroviario se descubre cómo se ha perdido una importante cota de mercado en la totalidad de las principales estaciones ferroviarias. Este hecho debe ser atendido con urgencia. Se necesita que se pongan en funcionamiento un paquete de actuaciones orientadas a propiciar el saneamiento de la cuenta de resultados del tren. Al tiempo, es fundamental impulsar una modernización funcional y operativa de la infraestructura ferroviaria. 


\section{Bibliografía}

ABAD, D., MONPÓ, R., NEBOT, F. y VAQUER. El Ferrocarril Alcoi-Gandía (El "Xitarra": 1833-1969. Edit. Institut Pare Eduard Vitoria. 1991. Alcoi.

ABAD, T. y CHIAS, P. Los ferrocarriles económicos de Asturias, pág., 137-159, en: LÓPEZ GARCÍA, M. (Direc.) La vía estrecha en Asturias. Ingeniería y construcción (1844-1972). Edit. Gran Enciclopedia Asturiana. 1995. Gijón.

ALBERT, W. "The Turnpike trusts" en: ALDCROFT, D. \& FREEMAN, M. (Edits.) Transport in de Industrial Revolution. Edit. Manchester University Press. 1983. Manchester.

ALDANA MARTÍNEZ, J. Azúcar, minería: los primeros ferrocarriles en Cuba (1837-1937). Edit. Oriente. Santiago de Cuba.

ALEGRÍA,M. F. (1984) "O caminho de ferro e a funçao detránsito nasrlaçoes comerciais luso-espanholas nasegundametade do século XIX e início do século XX”, en: (VV.AA.) II Coloquio Ibérico de Geografía. Edit. Universitat de Barcelona. Barcelona.

ALEGRÍA, M. F. (1987) A organizaçao dos transportes em Portugal (1850-1910). As vías e o tráfago. Disertaçao de Doutoramento (inédita). Lisboa.

ALEGRÍA, M. F. (1988) "Análise geográfica do transporte de mercadorias nos caminhos-de-ferro portugueses no século XIX”, en: VV.AA. Análise Social. Vol. XXIV, núm., 101-102. pág., 769-803

ANES, R. (1978) "Relaciones entre el ferrocarril y la economía española. 1865-1935", en: ARTOLA (Edit.) Los ferrocarriles en España. 1844-1943. 2 Volúmenes. Edit. Banco de España. Madrid. pág., 355-512.

ANES, R. (1988) "La industrialización de Asturias en el Siglo XIX: una transformación económica parcial”, en: FERNÁNDEZ DE PINEO, E. y HERNÁNDEZ MARCO, J. L. (Edits.) La industrialización del norte de España. Edit. Crítica. 1988. Barcelona. pág., 99-112.

ARTOLA, M. (1978) (Direc.) Los ferrocarriles en España. 1844.1943. Edit. Servicio de Estudios del Banco de España. Madrid.

ARTOLA, M. (1978) La acción del Estado, en: ARTOLA, M. (Direc.) Los ferrocarriles en España. 1844.1943. Edit. Servicio de Estudios del Banco de España. 1978. Madrid.1978. pág., 341-445.

MUÑOZ RUBIO, M., SANZ FERNÁNDEZ, J., \& VIDAL OLIVARES, J. (1999) Siglo y medio del ferrocarril en España, 1848-1998. Edit. Fundación de los Ferrocarriles Españoles. Madrid.

BERMEJO VERA, J. (1975) Régimen jurídico del ferrocarril en España (1844-1974). Estudio específico de RENFE. Edit. Tecnos.. Madrid.

BOUNEAU, C. (1990) Géographie et estructure du trafic ferroviaire de la Compagnie du Midi au début du XXe siécle, en: (VV.AA.) De Bayonne a Saint-Jean-Pied de Port. Edit. Fédération Historique du Sud-Ouest. pág., 253-275. 
CARON, F. (1981) "Ferrocarril y crecimiento económico en Francia en el siglo XIX", pág., en: (VV.AA.) Los ferrocarriles y el desarrollo económico de Europa occidental durante el siglo XIX. Edit. RENFE. Madrid. 105-125,

CARRERAS, A. (1999) Los ferrocarriles en Europa: algunas perspectivas bistóricas, en: MUÑOZ RUBIO, M., SANZ FERNÁNDEZ, J., \& VIDAL OLIVARES, J. Siglo y medio del ferrocarril en España, 1848-1998. Edit. Fundación de los Ferrocarriles Españoles. Madrid. pág., 33-54.

CASARES ALONSO, A. (1973) Estudio histórico-económico de las construcciones ferroviarias españolas en el Siglo XIX. Edit. Instituto de Desarrollo Económico. Madrid.

COMÍN COMÍN, F. (1983) "Comentarios en torno al ferrocarril y el crecimiento económico español entre 1855-1931”, en: Revista de Historia Económica, Vol. I., núm., 1. 1983. Madrid. pág., 181-196.

COMÍN COMÍN, F., MARTÍN ACEÑA, P., MUÑOZ RUBIO, M., y VIDAL OLIVARES, J. (1998) 150 años de Historia de los Ferrocarriles Españoles. Vol. I y Vol. II. Edit. F.F.E. Anaya. Madrid.

COMÍN COMÍN, F. (1999) "Los efectos económicos del ferrocarril sobre la economía española (1855-1835)”, en: MUÑOZ RUBIO, M., SANZ FERNÁNDEZ, J., \& VIDAL OLIVARES, J. Siglo y medio del ferrocarril en España, 1848-1998. Edit. Fundación de los Ferrocarriles Españoles. Madrid, pág., 255-272.

COMISIÓN EUROPEA. Challenges for the rail supply industry. Final Report. Junio. 1996. Bruselas.

DE CUADRA ECHAIDE, P. (1962) Problemas del transporte ferroviario español, en: Revista de Economía Española (Mayo). Madrid.

DÍAZ FERNÁNDEZ, J. A. La participación del transporte ferroviario en Galicia en el marco de la operatividad de un sistema de transporte intermodal e integrado: claves y perspectivas, en: LÓPEZ IGLESIAS, E., \& ARES FERNÁNDEZ, J., (Edis.) II Congreso de Economía de Galicia. Edit. USC. IDEGA. Pág, 273-302.

DÍAZ FERNÁNDEZ, J. A. "La oferta pública de transporte ferroviario en Galicia: contribución al desarrollo de la economía regional”, en: VV.AA. XXVIII Reunión de Estudios Regionales. Desarrollo Sostenible en la Europa de las Regiones. Edit. AECR. Universidad de Murcia. 2002. Murcia.

DÍAZ FERNÁNDEZ, J. A. (2002) El tren en Galicia. Aproximación a la politica ferroviaria: su contribución al desarrollo regional. Edit. Excma. Diputación Provincial de Pontevedra. Pontevedra.

DÍAZ FERNÁNDEZ, J.A. (2007) El sistema de transportes y comunicaciones terrestre en el desarrollo regional de Galicia. Edit. Universidad de Santiago.

FOGEL, R. W. (1972) Los ferrocarriles y el crecimiento económico de los Estados Unidos. Ensayos de historia econométrica. Madrid. 
GÓMEZ MENDOZA, A. Ferrocarriles y cambio económico en España, 1855-1913. Una nueva historia económica. Edit. Alianza. 1982. Madrid.

GÓMEZ MENDOZA, A. (1985) Ferrocarril y mercado interior en España (1874-1913). Volumen II. Manufacturas textiles, materias textiles, minerales, combustibles y metales. Edit. Banco de España. Madrid.

GÓMEZ MENDOZA, A. (1985) La industria del material ferroviario, 1884-1935. Edit. Banco de España. Mimeo. Madrid.

GÓMEZ MENDOZA, A. (1997) “Transportes”, en: Historia de España Menéndez Pidal, Vol. XXXIII. Los Fundamentos de la España Liberal (1834-1900). La sociedad, la economía y las formas de vida. Edit. Espasa-Calpe. Madrid. pág., 467-515

MUÑOZ RUBIO, M. (1995) RENFE (1941-1991) Medio siglo de ferrocarril público. Edit. Luna. Madrid.

MUÑOZ RUBIO, M., SANZ FERNÁNDEZ, J., Y VIDAL OLIVARES, J. Siglo y medio del ferrocarril en España, 1848-1998. Edit. Fundación de los Ferrocarriles Españoles. 1999. Madrid. 